NBER WORKING PAPER SERIES

\title{
DO LOW LEVELS OF BLOOD LEAD REDUCE CHILDREN'S FUTURE TEST SCORES?
}

\author{
Anna Aizer \\ Janet Currie \\ Peter Simon \\ Patrick Vivier \\ Working Paper 22558 \\ http://www.nber.org/papers/w22558 \\ NATIONAL BUREAU OF ECONOMIC RESEARCH \\ 1050 Massachusetts Avenue \\ Cambridge, MA 02138 \\ August 2016
}

We thank Rebecca Lee, Kim Pierson, Joel Stewart and Alyssa Sylvaria of the Providence Plan for their generosity and help with the data, Michelle Kollett of the RI Dept of Health and Darlene Price of the RI Office of Healthy Housing for their generosity and help with the data on certificates, and the John D. and Catherine T. MacArthur Foundation for financial support. We also thank Michelle Marcus, Elsa Mora, Molly Schnell and Ruby Steedle for outstanding research assistance as well as Pedro Dal Bó and seminar participants at the Harvard-BU-MIT joint seminar, the University of Wisconsin Institute on Poverty, Yale, LSE, PSE, the Rand Corporation, the New York Federal Reserve, University College London, and the NBER Summer Institute for helpful comments. The authors are solely responsible for any errors. The views expressed herein are those of the authors and do not necessarily reflect the views of the National Bureau of Economic Research.

NBER working papers are circulated for discussion and comment purposes. They have not been peer-reviewed or been subject to the review by the NBER Board of Directors that accompanies official NBER publications.

(C) 2016 by Anna Aizer, Janet Currie, Peter Simon, and Patrick Vivier. All rights reserved. Short sections of text, not to exceed two paragraphs, may be quoted without explicit permission provided that full credit, including ( $)$ notice, is given to the source. 
Do Low Levels of Blood Lead Reduce Children's Future Test Scores?

Anna Aizer, Janet Currie, Peter Simon, and Patrick Vivier

NBER Working Paper No. 22558

August 2016

JEL No. I24,J15,Q53,Q58

\begin{abstract}
We construct a unique individual-level longitudinal dataset linking preschool blood lead levels with third grade test scores for eight birth cohorts of Rhode Island children born between 1997 and 2005. Using these data, we show that reductions of lead from even historically low levels have significant positive effects on children's reading test scores in third grade. Our preferred estimates use the introduction of a lead remediation program as an instrument in order to control for the possibility of confounding and for considerable error in measured lead exposures. The estimates suggest that a one unit decrease in average blood lead levels reduces the probability of being substantially below proficient in reading by 3.1 percentage points (on a baseline of 12 percent). Moreover, as we show, poor and minority children are more likely to be exposed to lead, suggesting that lead poisoning may be one of the causes of continuing gaps in test scores between disadvantaged and other children.
\end{abstract}

Anna Aizer
Brown University
Department of Economics
64 Waterman Street
Providence, RI 02912
and NBER
anna_aizer@brown.edu
Janet Currie
Princeton University
316 Wallace Hall
Princeton, NJ 08544
and NBER
jcurrie@ princeton.edu

\author{
Peter Simon \\ Peter Simon, MD \\ Clinical Associate Professor \\ Brown University \\ Dept of Epidemiology \\ Box G-S121-2 \\ 121 South Main Street \\ psimon846@gmail.com \\ Patrick Vivier \\ Department of Community Health \\ Brown University \\ Box G-S121 \\ Providence, RI 02903 \\ Patrick_Vivier@brown.edu
}




\section{Introduction}

With recent findings of high levels of lead in the drinking water in Flint, MI and in schools in several urban districts, attention has focused once again on the dangers of lead poisoning. While child blood lead levels have declined dramatically over the past 30 years, current estimates suggest that 4.5 million households in the US are exposed to high levels of lead and that half a million preschool aged children have elevated blood lead levels (BLLs). The U.S. Public Health Service recently included the elimination of elevated blood lead levels as a goal in Healthy People 2020, the ten-year national objectives for improving the health of all Americans.

There is strong neurobiological and epidemiological evidence of a relationship between early exposure to lead and future negative cognitive and non-cognitive outcomes. However, the epidemiological evidence is correlational, and much of it based on studies of children with much higher blood lead levels than are common today. ${ }^{1}$ In response to recent epidemiological studies suggesting exposure to lower levels of lead than traditionally considered also negatively affects child outcomes, the CDC has eliminated the use of the term "level of concern” when referring to blood lead levels and lowered the threshold for which children should receive case-management

\footnotetext{
${ }^{1}$ Recent correlational epidemiological studies include: Chandramouli et al. (2009), Canfield et al. (2003), Lanphear et al. (2005), Nigg et al. (2010) and Wasserman (1997) which all document a significant relationship between relatively low levels of lead $(<10 \mathrm{ug} / \mathrm{ml})$ during childhood and cognitive and behavioral outcomes including ADHD and hyperactivity. McLaine et al. (2013) analyzes the RI data used here and shows an inverse relationship between blood lead levels and school readiness. Among children with BLLs below 5, 68\% scored above the benchmark levels, while among children with a BLL of at least 10, only $49 \%$ exceeded the benchmark. Rao, Reyes and Urzua (2015) estimate the impact of lead using child's proximity to a toxic waste site on future academic achievement in Chile. Some of the best known studies examining the effects of high lead levels are based on cohort level analyses of historical data. For example, Ferrie, Rolf and Troesken (2012) exploit variation in the use of lead water pipes across time and place in the early part of the $20^{\text {th }}$ century to estimate a negative relationship between exposure to leaded water and later intelligence test scores among WWII army enlistees. Other studies use a similar research design to link declining lead levels in US children in the 1970s and 1980s from the de-leading of gasoline to the dramatic declines in crime witnessed since the mid-1990s (See Masters et al. (1998), Reyes (2015), Nevin (2000 and 2007), Mielke and Zahran (2012), and Grönqvist, Nilsson and Robling (2014).
} 
services from 10 to $5 \mathrm{ug} / \mathrm{dl}$ in 2012 (CDC, 2012). However, it is unclear to what extent children with blood levels that are detectable but below this threshold are being harmed.

One reason for the lack of evidence on this point is that it is rare to have longitudinal data linking preschool BLLs with future test scores. An additional difficulty for identifying the effects of lead is that even with such data, at least some of the measured correlation between blood lead levels and outcomes could reflect omitted characteristics of households that are independently correlated with negative child outcomes. Confounding arises from the fact that children with higher lead levels are more disadvantaged: They are more likely to come from minority groups, to be poor, to live in single parent homes, and to have less educated mothers. Such a bias would tend to cause researchers to overstate the dangers of lead.

A second problem is that blood lead levels are imperfectly measured and it may be necessary to measure frequently in order to capture harmful exposures since lead does not remain in blood but is deposited in other body organs. Measurement issues of this type that add random noise to lead measures would lead to under-estimates of the effects of lead exposure.

Our study addresses these weaknesses in the literature using a unique dataset we constructed for the state of Rhode Island (RI). We start with all children who were born between January 1997 and September 2005 whose BLL was measured at least once before age 6. Rhode Island had a particularly aggressive program of testing for lead, and $80 \%$ of all three-year-old children in the state have at least one BLL measurement. Most have repeated lead measures (an average of three tests per child). We are able to match information on pre-school blood lead levels from the RI Department of Health (RIDOH) with the child's test scores from the RI Department of Education (RIDE) in order to examine the effects of preschool blood lead levels on third grade test scores. 
We are able to control for many possible confounders associated with neighborhoods and schools by including Census tract fixed effects as well as measures of average test scores in the child's school and grade. In order to deal with residual confounding as well as errors in measured lead exposure we use instrumental variables methods.

Our preferred instrumental variables estimates are based on policies implemented in RI in 1997 that required landlords to ensure that rental homes were free of lead hazards. These policies were adopted following statements from the Centers for Disease Control in 1997 urging states to prioritize lead testing and remediation that targets children at the highest risk (Jones et al, 2009). One RI state policy required the owners of any building in which a child had an elevated lead level to mitigate the lead hazard or face prosecution by the state Attorney General. A second policy applied to all landlords, regardless of whether a child had tested positive for lead, and required them to obtain "lead-safe certificates" in order to rent their properties. For this program, the state targeted the oldest urban centers of the state. We document that neighborhoods with a greater share of old housing (one of the primary sources of lead paint in RI), and with higher initial child lead levels (as measured in 1997), witnessed the biggest gains in the number of lead-safe certificates issued, and the biggest reductions in child lead levels. ${ }^{2}$ These neighborhoods were also predominantly African American and poor and remained so after the lead clean-up.

Since the policies were rolled out in a targeted way, we construct instruments by modelling the probability that a child's home was certified at the time of birth as a function of the number of certificates that had been issued in their census tract as of their year of birth, as well as family characteristics, and tract, year, and month of birth fixed effects. We then use

\footnotetext{
${ }^{2}$ Previous work has documented that individual blood lead levels decline in a household after a certificate has been issued (Rogers et al, 2014).
} 
these models to predict the probability that a child's home was certified at the time of birth, and use this predicted probability as an instrument for a child's lead level. By using the predicted certification measure we use all of the available information about certification in the census tract, abstract from the individual family’s decision to take up the certificate program (which may be endogenous), and base our estimates on the availability of the program in their census tract. We also demonstrate that the program successfully targeted poor and minority areas and that it did not result in gentrification of these areas.

Using this instrumental variable strategy, we find a one point decline in reading scores for each one unit increase in the mean of a child's blood lead levels, as well as a 3.1 percentage point increase in the probability of being “substantially below proficient” in reading (on a baseline of 12 percent). ${ }^{3}$ The census tract fixed effects estimates for math scores are about a third smaller than those for reading and statistically significant; however, the instrumental variables estimates for math scores are imprecisely estimated, though still suggestive of negative effects of lead. Point estimates suggest that a one unit increase in mean blood lead is associated with an increase of 2.1 percentage points in the probability of being substantially below proficient in math $(\mathrm{t}=1.43)$ on a baseline of 16 percent of children.

The rest of this paper is organized as follows. We first provide an overview of some of the previous research about the prevalence and effects of lead poisoning. This is followed by an overview of our data and estimation strategy, and then by the main results. We then discuss the implications of these results for some of the observed differences and trends in test scores before offering some conclusions about the continuing deleterious effects of lead on children and possibilities for remediation.

\footnotetext{
${ }^{3}$ Throughout, mean refers to the geometric mean which is typically used in this literature because it reduces the influence of outlier values.
} 


\section{II: $\quad$ Background}

\section{A: Lead Poisoning and the Measurement of Lead in U.S. Children}

Lead has no biological value and is toxic to the human body, regardless of the pathway of exposure (ingestion or inhalation). Lead is toxic because of its ability to inhibit or mimic the actions of calcium, thereby affecting all calcium-dependent biological processes. Many body systems including the renal, endocrine, and cardiovascular systems are affected by lead exposure but the nervous system appears to be the most sensitive target. Within the brain, exposure leads to damage in the prefrontal cerebral cortex, hippocampus and cerebellum (Finkelstein, Markowitz, and Rosen, 1998). Neurodevelopmental studies show that infants, children, and the developing fetus are at the greatest risk of toxicity (National Research Council, 1993). This sensitivity is due to the fact that children are more likely to ingest lead, and ingested lead is more likely to be absorbed from the gastrointestinal tract of children. Moreover, conditional on absorption, lead is more likely to affect the developing nervous system than the mature brain because the so-called "blood-brain" barrier is less effective in young children than in adults (Lidsky and Schneider, 2003).

The negative health effects of lead ingestion have been known since at least Roman times. But until the mid-twentieth century, health officials considered only severe cases of lead poisoning to be harmful. In the 1960s medical professionals recognized that less acute lead exposure also had harmful effects and began characterizing lead poisoning as epidemic (Berney, 1993). In 1970, the U.S. Surgeon General issued his first formal statement on lead poisoning, naming it a national health problem (U.S. Dept. of Health, Education and Welfare, 1970). Since then, American children's exposure to lead has declined dramatically, due largely to two major 
regulatory changes involving the elimination of lead from gasoline and from household paint. ${ }^{4}$ Coincident with this decline, the share of pre-school age American children with blood lead levels in excess of $10 \mathrm{ug} / \mathrm{dl}$ has likewise declined from $8.6 \%$ to $1.4 \%$ over the period 1988 to 2004, with declines across all groups, but especially for historically high-risk groups of children (Jones et al, 2009).

Despite substantial progress, lead has remained a significant hazard especially in urban areas due to geographic concentrations of lead paint in deteriorating older homes, residual lead in soil at former industrial sites, and residual lead in soil near high traffic areas (Lanphear et al 1998; Levin et al, 2008).

Even conditional on living in an urban setting, there may be important differences in exposure to lead by socio-economic status, which could potentially confound the estimated effects of lead exposure. For example, the hazards associated with lead-based paint can be reduced by painting over old paint and ensuring that living areas are free of paint chips and dust. To the extent that more educated or wealthier families are more likely to take these precautions, similar exposures to old housing within an urban area are more likely to more negatively affect the most disadvantaged. ${ }^{5}$ For both these reasons, disparities in child BLLs by race and income remain, with African American and poor children two to three times as likely to have elevated lead levels, defined as above 5 micrograms per deciliter (CDC, MMWR 2013). ${ }^{6}$

\footnotetext{
${ }^{4}$ The key regulations and legislation that reduced exposure to lead included the 1970 Lead Paint Poisoning Prevention Act, the Clean Air Act, and Environmental Protection Agency rules regarding leaded gasoline.

${ }^{5}$ There is also evidence that nutrition and cognitive stimulation can mitigate some of the deleterious effects of lead (Billings and Schnepel, 2015).

${ }^{6}$ Based on analysis of the 1999-2002 NHANES, the CDC reported that the average blood level for children aged 1-5 was $1.9 \mathrm{ug} / \mathrm{dL}$, but for African American children this figure was 50\% higher $(2.8 \mathrm{ug} / \mathrm{dL})$ and $30 \%$ higher for low income households (2.5 ug/dL) (CDC MMWR, 2005).
} 
How many children suffer from lower levels of lead exposure, and how much such exposure has affected their outcomes is not easy to determine. The best national data comes from the National Health and Nutrition Examination Survey (NHANES), which draws venous blood from a nationally representative cross-sectional sample of children. Unfortunately, the nature of this data set does not allow an examination of the relationship between preschool blood lead levels and later child outcomes.

Another difficulty with having only a single measure is that the half-life of lead in blood is relatively short (36 days). As such, BLLs only capture very recent exposure and will not necessarily capture the amount of lead that has settled in body organs and bone. ${ }^{7}$ Hence a single blood lead measure may be an unreliable indicator of lead exposure.

A second measurement issue making multiple measures per child useful is that error can arise from contamination of the blood sample especially when the sample is a capillary sample (also known as a finger prick). Capillary samples are common due to their lower expense and degree of discomfort to the child. Even without contamination, there is significant error in measurement, with greater error characterizing capillary measures. According to the CDC, the "ratio of imprecision to measurement value, particularly at BLLs $<10 \mathrm{ug} / \mathrm{dL}$, is relatively high" (MMWR, 2002). ${ }^{8}$ Measurement error can lead to considerable attenuation bias in the estimated

\footnotetext{
7 "Deleterious health effects of lead resulting from long-term lead exposure will only be correlated with current blood-lead levels if lead exposure has been relatively constant over a long period of time, up to the time of sampling." Moreover, "Physiologically, the measurement of lead in blood is not a direct assessment of target organ dose, since the red cell is not a critical target for lead toxicity. Kinetically, blood is not a good analog for critical targets, such as soft tissue, because of the relatively short half-life of lead in blood as compared to target organs or bone.” Mount Sinai School of Medicine. Accessed on 12/16/2014: http://research.mssm.edu/xrf/why.html ${ }^{8}$ According to the CDC guidelines "Federal regulations allow laboratories that perform blood lead testing to operate with a total allowable error of $\pm 4 \mathrm{ug} / \mathrm{dL}$ or $\pm 10 \%$ whichever is greater" (MMWR, 2007).
} 
effect of lead, as we demonstrate below. These considerations mean that having repeated measures for most children is a signal advantage for our study. ${ }^{9}$

\section{B. Lead Mitigation Policies in RI}

Rhode Island, and particularly its urban areas, is characterized by old housing, with much of it (43 percent) built prior to WWII, and therefore containing the greatest concentration of leaded paint. As a result, many of the state's children are exposed to lead through deteriorating lead-based paint, with minority and low income children disproportionately exposed. ${ }^{10}$ As is the case nationally, this disproportionate exposure is due largely to the residential segregation of the poor, and especially of African Americans, in the four core urban areas of the state located within Providence County. U.S. Census data reveals that 81 percent of the homes in Providence County were built prior to 1978 and 49 percent before WWII. Comparable numbers for the rest of the state are 68 and 27 percent.

In an effort to reduce childhood exposure to lead, in 1997 RI established two programs to encourage mitigation of lead hazards in old homes. The first required all owners of homes in which an elevated lead level was found to mitigate such hazards. Once the home was mitigated, an inspection would be performed and the Department of Health would issue a certificate (a DOH certificate). Non-compliant landlords were referred to the state Attorney General for

\footnotetext{
${ }^{9}$ We believe that mismeasurement of blood lead levels is generally random and uncorrelated with test scores, and so should lead to attenuation bias.

${ }^{10}$ Previous work has established that within RI, children living in high (top quintile) poverty neighborhoods are nearly four times more likely to have elevated BLLs than those in low (bottom quintile) poverty neighborhoods (Vivier et al, 2011).
} 
prosecution. The second program was administered by the RI Housing Resources Commission (HRC) and required all landlords to mitigate lead hazards in the homes they rented - regardless of whether an elevated lead level had been reported. When mitigation was received, a lead-safe certificate was issued (an HRC certificate).

The state provided landlords with training in the importance of lead hazard mitigation, information and training on how to reduce lead hazards in the homes in the least costly manner, and even provided low interest loans to landlords to help them to comply. Section 8 voucher rentals and family day care centers were prioritized. Few resources were devoted to enforcement and though non-compliance was illegal, landlords were typically not penalized for noncompliance. However, landlords who did not have a lead-safe certificate could be sued in civil court if children living in their homes were found to have elevated lead levels.

Over the period 1997-2010, the total number of lead-safe certificates issued to landlords increased from 333 to 47,734 (Appendix Table 2). Of these, 31,104 were HRC certificates indicating a regulatory approach that was far more likely to involve carrots (e.g. training and assistance to landlords to help them to comply in addition to protection against civil suits) than sticks in the form of potential prosecution by the state Attorney General.

Figure 1 shows the distribution of certificates across the state and shows that the program was targeted at the four oldest "core cities” of RI. Within each area, the state contracted with community based non-profit organizations to provide outreach to landlords in the areas where the housing stock was the oldest, the lead burden was the greatest and the families were the most disadvantaged.

As a result of this targeted outreach, the census tracts that experienced the greatest increase in certificates issued per capita were characterized by older housing stock, a greater 
share of children with high lead levels in 1997, and a greater share of poor families as shown in Figure 2, which plots the number of certificates per capita against these characteristics of census tracts. $^{11}$

A potential concern about using lead-safe certificates to construct instruments for variation in blood lead levels is that areas that saw greater growth in certificates may have been characterized by other changes in demographic composition that could influence test scores. Figure 3 shows that this does not appear to be the case. Tracts with the greatest increase in certificates do not appear to have experienced other demographic changes over the period 19972010. There is no apparent relationship between changes in certificates per capita, and changes in the share black, the share poor, median family income, or housing prices. This is not surprising given that the HRC policy in particular was designed and implemented in such a way as to minimize the costs of mitigation to the landlord.

Thus we argue that the growth in the number of lead safe certificates within a neighborhood over time provides exogenously occurring variation in exposure to lead which forms the basis of our preferred instrumental variables strategy.

III: $\quad$ Data and Trends

A. Sources of Data

Our sample consists of all children born in the state of RI between January 1997 and September 2005, who have data on at least one BLL measure before the age of six, and who are enrolled in any RI public school. The data on BLLs comes from the RI Department of Health

\footnotetext{
${ }^{11}$ Certificates are scaled by 100.
} 
(RIDOH) and includes the age at each test, the test method (capillary or venous), the census tract where the child lived at the time of the test, and the BLL. Educational outcomes come from the RI Department of Education (RIDE) and include NECAP ${ }^{12}$ scaled test scores in third grade, gender, race, ethnicity, and school lunch (free or reduced) status. The third source of data are birth certificates of children born in RI, which we have for $85 \%$ of our sample (the remainder moved to the state as young children.) These data include maternal education, marital status at birth, and the child's birth order and birth weight. Since confidential versions of these data contain information about the child's address, we are able to merge these data with data collected on whether and when a lead-safe certificate was issued for a given dwelling. ${ }^{13}$

The final sample includes roughly 71,000 RI children born between January 1997 and September 2005 with linked BLL and educational test score data. Details on construction of the sample can be found in Appendix Table $1 .{ }^{14}$ Compared with a national lead screening rate of only 25 percent, 80 percent of all children with a RI birth certificate are screened at least once and the screening rate remained constant throughout the study period, suggesting that the demographics of children screened also likely remained constant. Using vital statistics data to compare the maternal characteristics (race, education, and marital status) of children with a blood lead level (80\%) to those without a blood lead level (20\%), we find that those with a lead screen are slightly more disadvantaged along most measures with the exception of birth weight

\footnotetext{
${ }^{12}$ NECAP stands for the New England Common Assessment Program. It is a series of exams developed collaboratively by the New Hampshire, Rhode Island and Vermont departments of education, with assistance from the National Center for the Improvement of Educational Assessments. The NECAP tests measure students' academic knowledge and skills relative to Grade Expectations which were created by teachers from the three states. ${ }^{13}$ This merge was performed by the Providence Plan. We were provided with a de-identified analysis file that excluded child name and address.

${ }^{14}$ In addition, we drop approximately 7,000 children with matched birth, BLL and test score data because they are missing Census tract level measures that we use as controls in our estimation models.
} 
which is the same for the two groups. ${ }^{15}$ Appendix Table 1 also shows that among those with a lead level, those matched with RIDE data are slightly more disadvantaged than those who we were not found in RIDE data (presumably because they attended private school). However, children with matched lead-RIDE data are representative of all children in the RIDE data (all public school students).

Table 1 provides an overview of our data, for the whole sample and for various subsamples. Children have on average 2.7 BLL measures over the first 72 months of life, after which they are typically not tested. ${ }^{16}$ Minority and disadvantaged children actually receive more tests, suggesting that they may be more likely to have BLLs that call for further monitoring. To construct a single measure of BLLs we calculate the geometric mean, reducing the influence of outliers. This procedure is consistent with the existing literature.

The mean BLL is 3.1, which is well below the CDCs threshold for medical intervention of 5 micrograms per deciliter. African American and Hispanic children both have higher mean levels, as do children who always receive free school lunch (4.2, 3.6, and 3.9, respectively). ${ }^{17}$ Minority children are also more likely to have high mean scores, with 30\% of African American, 23\% of Hispanic and 27\% of always free lunch children having levels above 5 (compared to 14\% of white children). The corresponding numbers for mean levels above 10 micrograms per deciliter are 5\%, 3\%, and $4 \%$ respectively. Note that it is not at all unusual in RI for a child to have a single BLL above 5 or even above 10 micrograms per deciliter - overall, $40 \%$ of children have at least one measure above 5 and 9\% have a measure above 10. The discrepancy between

\footnotetext{
${ }^{15}$ As Appendix Table 1 shows, 12,008 children with matched preschool BLL and $3^{\text {rd }}$ grade test score data are missing birth certificate data, presumably because they were not born in RI. Rather than drop these children, which would result in an unrepresentative sample, we impute vital statistics measures using their other characteristics.

${ }^{16}$ When there is a capillary and venous sample available for the same month, we drop the capillary measure because the venous one is likely to be more accurate.

${ }^{17}$ Of course there is considerable overlap in minority and free lunch status with $56 \%$ of African American children and $61 \%$ of Hispanic children being always eligible for free lunch.
} 
single measures and mean measures likely reflects measurement error in the tests, as we will argue further below.

Academic test scores range from 0-80, with an average score of 45.5 for reading (standard deviation of 13) and 42.2 for math (standard deviation of 13). Twelve percent of children were "substantially below proficient” (defined as a score less than 30) in reading, and 16 percent for math. Again, there is considerable variation by race, ethnicity, and free lunch status with, for example, the fraction of children who are substantially below proficient in reading reaching 19 percent for African Americans, 22 percent for Hispanics, and 21 percent for children who were always eligible for free lunch.

Seventeen percent of the children live in a home that received a lead-safe certificate at some point during our sample. This fraction is much higher for poor and minority children at 31 percent for African Americans, 35 percent for Hispanics, and 32 percent for children who were always eligible for free lunch. These numbers suggest that the certificate program had significant penetration and that it was in fact targeted at the areas with the highest initial lead burden. The number of children whose homes had received a lead safe certificate at the time of their birth is smaller, reflecting the fact that the first birth cohorts in our data had almost no exposure to the certification program.

The rest of Table 1 summarizes characteristics drawn from the birth certificate and shows that in addition to having higher BLLs, poor and minority children had lower birth weight, and mothers with much less education. Since both of these factors have been independently shown to be associated with lower children's test scores, the table shows the potential for confounding of the relationship between BLLs and children's test scores. 
Table 1 provides a static picture. There were however dramatic reductions in blood lead levels in a very short period of time. Figure 4 shows the distribution of a child's average BLLs for the cohorts born in 1997 and 2005. Clearly, the whole distribution shifts to the left, with a virtual collapse in the part of the distribution above 5 milligrams per deciliter.

Table 2 therefore focuses on changes between the first and last birth cohorts in our data for BLLs, exposure to the housing certificate program and test scores. The first two columns indicate that blood lead levels declined by 42 percent relative to base levels in eight years. This is a very rapid decline which we attribute in part to the introduction of the lead-safe certificate program. Consistent with this interpretation, the next two columns show that the fraction of children with a certificate in place at the time of the birth increased dramatically among children in the most disadvantaged groups. For example, in the 1997 birth cohort only 2 percent of sample African American children lived in a home that had been certified lead-safe at the time of their birth; by 2005, 12 percent of sample African American children lived in a home that had been certified as lead safe from the time of their birth.

Third grade test scores rose across birth cohorts in all demographic groups, while the fraction scoring substantially below proficient declined. However, the gains were greatest in the groups that were most affected by the certificate program. For instance, among children who never participated in the free lunch program, reading test scores rose by 5.9 percent and the percent who were not proficient in reading fell from six to four percent. Among children who were always eligible for the free lunch program, reading test scores rose by 11.2 percent and the percent who were substantially below proficient in reading fell from 27 to 18 percent, a remarkable improvement. Of course these gains might have been caused by other changes targeted at poor and minority children, the most likely candidate of which is educational policies, 
as discussed below. Hence, in our models we will also show estimates controlling for third grade reading scores in the child's school and cohort, which should capture any other efforts targeting children in these neighborhoods and schools.

\section{Estimation Strategy}

Our preferred instrumental variables estimates exploit variation in lead exposure induced by the policy changes that required landlords to certify that their homes were lead safe. A concern with this strategy relates to the fact that certificates may be correlated with changes in local schools. Neighborhoods that were targeted to received more certificates might have also received increases in school resources following the passage of No Child Left Behind in 2002, for example. To address this concern, we control for the average reading test scores of all the other students in a child's school and grade. This control captures potential changes in schools (policies, resources, student composition, etc) that might be relevant to the index child's test scores.

A. Lead Levels and Future Child Cognitive Achievement - OLS and FE Estimates

We wish to estimate the impact of preschool lead levels on future academic achievement as measured by reading test scores. We begin with estimates of the following equation:

(1) $\quad \mathbf{Y}_{\mathrm{i}}=\beta_{0}+\beta_{1} \mathbf{L e a d}_{\mathrm{i}}+\beta_{2} \mathbf{X}_{\mathrm{i}}^{\mathrm{c}}+\beta_{3} \mathbf{X}_{\mathrm{i}}^{\mathrm{m}}+\beta_{4} \mathbf{X}_{\mathrm{tn}}^{\mathrm{n}}+\boldsymbol{\tau}_{\mathrm{n}}+\boldsymbol{\tau}_{\mathrm{t}}+\varepsilon_{\mathrm{i}}$.

where $\mathbf{Y}_{\mathbf{i}}$ is the scaled reading or math test score in grade 3, or an indicator equal to one if the child was substantially below proficient in one of these subjects. Leadi is the geometric mean of 
the multiple BLLs taken for each child. The vector $\mathbf{X}^{\mathrm{c}}$ includes the child's race (indicators for white, black, Hispanic, Asian and other), birth weight, gender, and a measure of the child's free/reduced lunch status (always free lunch, sometimes free lunch, never free lunch). The vector $\mathbf{X}^{\mathrm{m}}$ includes maternal educational attainment (indicators for less than HS, HS and some college or more) and marital status at birth. ${ }^{18}$ The vector $\mathbf{X}^{\mathrm{n}}$ includes time-varying neighborhood (census tract) characteristics from census data including the share poor, median family income, and the share of housing units built post-1978. ${ }^{19}$ All variants of this model include $\boldsymbol{\tau}_{\mathrm{t}}$, a vector of year of birth and month of birth fixed effects. We compare OLS estimates to those that also include $\boldsymbol{\tau}_{\mathrm{n}}$, a vector of census tract fixed effects.

As discussed above, in addition to the usual concerns about confounding, which may or may not be adequately addressed by including census tract fixed effects, estimation is complicated by the fact that there may be considerable measurement error in blood lead levels. In order to explore the importance of this feature of the data, we follow Ashenfelter and Krueger (1994) and Chalfin and McCrary (forthcoming), who have multiple measures of their variables of interest and use one measure as an instrument for another to estimate the degree of measurement error and downward attenuation bias in OLS estimates of education on earnings and police on crime, respectively. In our context, we can estimate models using the subset of children who have both venous and capillary measures and using the former as instruments for the later. We also estimate models in which we instrument a randomly chosen test result for each child using the mean of the other available tests. Although our multiple measures of child lead exposure were taken at different times and may capture differences in the child's underlying

\footnotetext{
${ }^{18}$ Because children who were not born in RI do not have data from birth certificates (birth weight and maternal education), we impute the average bw and maternal education for these individuals and include indicators for imputation.

${ }^{19}$ We use linear interpolations between census years for other years.
} 
lead levels, each measure can still be interpreted as an (imperfect) measure of the underlying level of lead exposure during early childhood.

The results of these exercises, presented later, suggest that measurement error is a considerable problem and that it tends to lead to attenuation in the estimated effect of lead exposure on test scores. Hence, we turn to instrumental variables estimation using an instrument based on the lead-safe certificate programs that addresses both potential endogeneity or confounding and attenuation bias due to measurement error.

\section{B. Instrumental Variables Estimates}

For each child we know whether their place of residence during their preschool years had received a lead-safe certificate as of their birth date. ${ }^{20}$ Issuance of a certificate indicates that any lead hazard in the home had been mitigated, so it should be associated with lower BLLs. However, whether a particular residence receives a certificate or not is at least partly endogenous. While we measure the presence of a certificate in the home as of the date of birth of the child so that certificate status cannot be a function of the child's lead level (ie, parents with a child with an elevated lead level seek out a home with a certificate), it might still be the case, for example, that among otherwise similar parents, those that seek out lead testing and lead mitigation are also likely to have children with higher test scores.

Hence, rather than using the actual measure of whether there was a certificate or not in the child's home as an instrument, we construct a predicted certificate measure based on censustract level measures of the availability of the various lead-safe certificate programs: The number of certificates issued by the DOH in the past 5 years (recall that these are required if a child tests

\footnotetext{
${ }^{20}$ We have the address (and date) at each blood test but use the address of the first test.
} 
above a certain threshold), the number of certificates issued by the HRC in the past five years (required of all landlords), the total number of certificates (DOH and HRC) that had been issued. By using the "predicted certificate”, we purge the instrument of any potential endogeneity associated with the take-up decision. The prediction equation takes the form:

(2) Certificate@Birth $=\alpha_{0}+\alpha_{1}$ Certificatesnt-5 $+\alpha_{2}$ EverCertificate $_{\mathbf{i}}+\alpha_{3} \mathbf{X}_{\mathrm{i}}^{\mathrm{c}}+\alpha_{4} \mathbf{X}_{\mathrm{i}}^{\mathrm{m}}+$ $\alpha_{5} X_{t n}^{n}+\gamma_{n}+\gamma_{t}+\mu_{\mathrm{i}}$.

Here Certificate@Birthi indicates that the child lived in a house that had been certified lead-safe as of the time of the child's birth and Certificatesnt-5 is a vector of census tract level measures of the availability of the certificate programs as of the child's year of birth (as measured by the number of certificates issued in the past 5 years divided by the number of old homes in the census tract, excluding the focal child). EverCertificatei is an indicator equal to one if the child's home ever received a certificate. We include this indicator in order to control for the fact that some homes require lead remediation while others do not and given that it is a proxy for low quality housing, it is included in the second stage as well. By including this variable, we are focusing on the timing of the certificate intervention - conditional on the house needing and eventually receiving remediation, was the remediation done in time for this particular child to benefit? The other variables are as defined above and include child, mother, and census tract characteristics as well as year, month and census tract fixed effects. Importantly, the instrument, predicted certificate, is not a function of $\mu_{\mathrm{i}}$, all the unobservable characteristics of the child or family that influence certificate take-up that might also be correlated with test scores.

Having constructed the instrument, we proceed with instrumental variables estimation. The first stage is given by: 


$$
\begin{aligned}
& \text { Leadi }_{i}=\alpha_{0}+\alpha_{1} \text { Certificate@Birth }{ }^{*}+\alpha_{2} \text { EverCertificate }_{i}+\alpha_{3} \mathbf{X}_{\mathrm{i}}^{\mathrm{c}}+\alpha_{4} \mathbf{X}_{\mathrm{i}}^{\mathrm{m}}+\alpha_{5} \mathbf{X}_{\text {tn }}^{\mathrm{n}} \\
& +\gamma_{\mathrm{n}}+\gamma_{\mathrm{t}}+\mu_{\mathrm{i}},
\end{aligned}
$$

where Certificate@Birthi* is the predicted value of Certificate@Birthi generated by equation (2). Finally, we estimate an instrumental variables version of equation (1) in which Leadi is replaced with the predicted geometric mean BLL from (3):

$$
\mathbf{Y}_{\mathrm{i}}=\beta_{0}+\beta_{1} \text { Leadi }^{*}+\beta_{2} \text { EverCertificate }+\beta_{3} \mathbf{X}_{\mathrm{i}}^{\mathrm{c}}+\beta_{4} \mathbf{X}_{\mathrm{i}}^{\mathrm{m}}+\beta_{5} \mathbf{X}_{\mathrm{tn}}^{\mathrm{n}}+\boldsymbol{\tau}_{\mathrm{n}}+\boldsymbol{\tau}_{\mathrm{t}}+\varepsilon_{\mathrm{i}} .
$$

To address concern that the areas of the state that received more certificates are the most disadvantaged and that schooling inputs in these neighborhoods may have increased over this period, we include a control for the average third grade reading test scores in the child's school (calculated as the leave out mean, i.e. leaving out the index child in each case, for all children with third grade test scores in the same school and cohort) and present estimates with and without this control. To address concerns that these unobserved improvements occurred not within the school but in the neighborhood, we also estimate models including a linear trend for each initial 1997 census tract reading score. This control is intended to capture the idea that tracts that started with the lowest scores may have improved the fastest because of other unobserved investments targeted to these tracts.

\section{Results: Effects of BLLs on Third Grade Test Scores}

OLS and census tract fixed effects estimates of the effect of preschool BLLs on third grade test scores are shown in 3a (for reading) and 3b (for math). The first column shows estimates that control only for gender, race and free/reduced lunch status (that is, the information available from the RI Department of Education). The second column adds information obtained 
from the birth certificate, as well as time varying census tract characteristics. These additions reduce the estimated effects of lead from -.456 per unit of lead to -.326 for reading and from .348 to -.216 for math, suggesting that confounding could be a concern in studies with inadequate controls for family background.

Columns (3), (4), and (5) add census tract fixed effects as well as school and grade level measures (column 4) and linear trends in the 1997 census tract test scores. These additions have relatively little impact on the coefficient estimates. This is consistent with a meta-analysis of eight studies conducted by epidemiologists in which they reported that adding more family controls to a relatively parsimonious set (maternal schooling and IQ, the HOME score, birth weight, and city) did little to alter the relationship between lead and IQ in children (Rothenberg and Rothenberg, 2005), suggesting little residual confounding.

The estimated effects of lead in these models are strongly statistically significant but relatively small: The column (4) estimates suggest that a one point increase in mean BLLs is estimated to reduce reading scores by .306, and math scores by .193. However, as discussed above, these may well be under-estimates of the true effect given the difficulties of properly measuring BLLs.

The issue of measurement error is explored in Table 4. The first three columns focus on the subset of 12,002 children who had both capillary and venous tests. Venous tests are known to be far more accurate than capillary (finger prick) tests. Consistent with this, we see that estimating the effects of lead using the average of all capillary tests (column 1) produces a much lower estimate of the effect of lead than using the average of all venous tests (column 2). Given two noisy measures of the same underlying concept, and assuming that the measurement errors 
in the two tests are independent, we can use one set of tests as an instrument for the other tests, as is done in column (3). This IV estimate is much larger than the OLS estimate reported in column (2): For reading the estimated coefficient rises from .315 to .537 in absolute value, and for math the value rises from .201 to .343.

Columns (4) through (6) illustrate this issue in another way. Column (4) shows estimates based on a randomly drawn test. Column (5) shows estimates based on the average of all other tests. The latter are somewhat larger than those in column (4). Finally, in column (6) we instrument the randomly drawn test with the average of all other tests. Once again, this estimate is roughly three times larger than those produced without using instrumental variables techniques. These experiments suggest that finding a valid instrument for children's mean BLLs is likely to yield larger estimated effects of lead.

We then proceed to generate the instrument for the IV regressions. Table 5 shows three different models of whether the child's preschool home had a lead safe certificate at the time of the child's birth (estimates of equation 2). Column (1) has the total number of certificates, and the number of certificates squared. Column (2) includes interactions of the total number of certificates with the characteristics of the household, allowing for the fact that different types of households might be more likely to receive certificates within a census tract. Column (3) differentiates between types of certificates.

Not surprisingly, the census tract-level measures of certificate program activity are strongly predictive of whether there was a certificate in the child's preschool home as of the child's birth. The interactions in column (2) further suggest that the total number of certificates in the tract was more highly predictive of having a certificate in the child's home if the child was 
African American or Hispanic, or always eligible for free lunch. Of course, whether the home ever received a certificate over the course of our sample period is also highly predictive as are some of the census tract level variables such as median family income and the share of newer housing, both of which are negatively associated with having a certificate in the home.

Table 6 shows the results of using a predicted certificate measure based on the model in column (3) of Table 5 in the first stage equation (3). The overall estimated effect of a predicted certificate on blood lead levels is strongly negative, and is much more strongly negative for the groups with high initial BLLs that we saw were most impacted by the new lead mitigation policies enacted in 1997. For white children in the 2005 birth cohort, 2 percent lived in a house where a certificate had been issued as of the time of birth. Thus, the overall coefficient of -8.388 suggests that a certificate reduced blood lead levels by only .17 micrograms per deciliter. Among African-Americans in the 2005 birth cohort, Table 2 shows that 12 percent of children lived in homes that had been certified by the time of the child's birth. The coefficient of -15.49 for African-Americans suggests that blood lead levels would be reduced by almost two micrograms per deciliter in these certified homes. This number can be compared to the coefficient of 1.958 on the indicator for whether the "home ever had a certificate." This comparison suggests that black children in homes that had not yet received a certificate had BLLs two micrograms per deciliter higher than other black children and that this gap was reduced to zero when a certificate was obtained.

Table 7 presents our best estimate of the effects of preschool blood lead levels on third grade test scores. The first column reproduces the models shown in column (3) of Table (3) for comparison. The second column shows the IV model (with census tract fixed effects). The third column adds several additional controls including the leave-out mean of the relevant test score in 
the child's school and grade; the percent below proficient on the test; a race specific linear time trend; and a free lunch specific linear time trend. These later two sets of controls are intended to capture any state-wide initiatives aimed specifically at improving test scores among AfricanAmerican or poor students that might have set them on a different time trend than other students.

The first panel of Table 7 focuses on reading scores and shows that the instrumental variables estimates of the effects of lead are roughly three times greater than the Table 3 OLS estimates with census tract fixed effects. As discussed above, this result likely reflects both correcting for measurement error, and the large impact of the certificate program on "treated" individuals. Moving from column (2) to column (3) does attenuate the estimated effect somewhat, but it remains three times larger than the column (1) estimate.

Another way to explore the idea that the program had a large impact on the treated children who were more likely to be poor, African American and Hispanic, is to explore movement in the tail of the reading score distribution, where these children are disproportionately represented. Therefore, in the second panel of Table 7 we investigate the estimated impact of lead on the probability of being substantially below the cutoff for reading proficiency. Again, the IV estimates in columns (2) and (3) are considerably larger (four times) than the OLS-census tract fixed effects estimates in column (1): Column (3) suggests that a one microgram per deciliter increase in mean BLLs is associated with a 3.1 percentage point reduction in being less than proficient in $3^{\text {rd }}$ grade reading scores.

The next two panels present estimates for math test scores and the probability of being substantially below proficient in math. These estimates are much less precise than those for reading. The IV estimates for the continuous math score are not statistically significant in either 
specification shown. For the math proficiency measure, the IV estimate in column (2) is significant at the $10 \%$ level $(\mathrm{t}=1.8)$, while the standard error rises in column (3) so that the estimate is not significant at conventional significance levels. Nevertheless, the pattern of estimates is similar to those for reading with the IV estimates being roughly four times larger than the OLS-census tract fixed effects estimates in column (1).

\section{Discussion}

Between the 1997 and 2005 birth cohorts the geometric mean of blood lead levels fell by 1.5 milligrams per deciliter among whites but by 2.8 and 2.4 milligrams per deciliter among African Americans and Hispanics, respectively (Table 2). Table 2 also suggests that whites were much less impacted by the certificate program. If we attribute the greater decline in blood lead levels in these minority groups to the targeted nature of the lead-safe certificate program, then Table 7 suggests that the program increased mean reading scores among African Americans and Hispanics by $1.27\left((2.8-1.5)^{*} .977\right)$ and $.88((2.4-1.5) * .977)$ points, respectively. Thus, the program would have accounted for a third (a fifth) of the gain in reading scores among African Americans (Hispanics).

Another way to think about these gains is in terms of reductions in the gap in reading test scores between whites and African Americans or Hispanics over this period given that the policy targeted children in oldest homes in the state which are disproportionately African American and Hispanic. For African American children, the gap closed from 8.3 to 7.3 points over this period and for Hispanic children from 9.9 to 8.3 points. If we assume the policy primarily affected children with the highest BLLs (the top 10\% which fell from 7.06 to 4.21 over this period), we calculate that the policy resulted in an increase in test scores among African American children 
of $0.75,0.44$ for Hispanic and 0.18 for white children. ${ }^{21}$ Thus, the policy change explains $44 \%$ (16\%) of the closing of the Black (Hispanic)-white test score gap observed over this period. If we examine the closing of the gap not in average test scores, but in the share of children substantially below proficient, the policy change can explain $57 \%$ and $19 \%$ of the closing of the Black-white and Hispanic-white gaps, respectively, over this period. Thus, these results suggest that environmental regulations targeted at hazards that disproportionately impact minority children may have advantages beyond improvements in health.

In addition to quantifying the negative effect of lead, our focus on the lead-safe certificate program may offer some useful lessons for lead remediation. The program focused on low cost lead remediation (rather than on removing all lead-bearing materials which would be much more costly). It offered more carrots than sticks in the sense that while some landlords were prosecuted, many others were offered training, loans, and protection against future lawsuits (in the form of the lead-safe certificates themselves). And the program was highly targeted in the areas most in need of remediation.

Probably because of these factors, the program was relatively inexpensive with annual spending of approximately a half a million dollars for FY2014. If we assume the same level for each year of the program (which is an overestimate given the program ramp up in the early years), the total cost would be $\$ 4$ million. Over our entire sample period only three percent, or 2120 children had a certificate in place at the time of birth. If we assume that these children would otherwise have had greater lead exposure, then the program reduced lead exposure and raised reading scores among these children at a cost of approximately $\$ 1886$. per child.

\footnotetext{
${ }^{21}$ This calculation is made by multiplying the share of black children in the top $10 \%$ of the BLL distribution (0.27) by the change in the BLLs of those in the top $10 \%$ of the distribution over this period $(7.06-4.24=2.82)$ and by the IV estimate of the impact of a 1 unit change in BLLs on reading test scores (0.977).
} 
Moreover, since future cohorts will continue to benefit from lead safe environments, the cost per child benefitted will likely fall over time. These results suggest that practical targeted lead remediation programs of this kind can have dramatic effects.

\section{VII: Conclusions}

Our study contributes to an evolving understanding of the hazards of even low levels of lead exposure among young children. It is to our knowledge the first study to utilize a large and representative data set linking preschool lead levels with future school test scores and to develop a research design aimed at overcoming several threats to inference. These threats include potential confounding due to the concentration of lead exposure in disadvantaged families and neighborhoods, and the difficulties involved in measuring lead exposure itself.

In order to address these problems, we develop a novel instrumental variables strategy based on a lead-safe certificate program that was rolled out in Rhode Island starting in 1997. As we document, the program targeted areas of the state with the oldest housing (and thus the greatest risk of lead poisoning) where poor and minority children reside, and there was considerable variation in certificate activity across both time and space. However, because it is possible that, even within neighborhoods, take up of the program was endogenous, we predict the timing of take up in the child's preschool home using the penetration of the program into the neighborhood, and we then use this predicted take up measure as the instrument for the child's own lead exposure.

While all of our estimates suggest that preschool blood lead levels have negative effects on future test scores, our instrumental variables estimates suggest that even after controlling for census tract fixed effects, the true effects are three to four times greater than OLS estimates. We 
find that reading scores fall approximately one point for each one microgram per deciliter increase in blood lead levels. The effects are larger at the lower end of the score distribution, so that a one microgram per deciliter decline in lead reduces the probability of being substantially below proficient in reading by 3.1 percentage points. Our results also suggest that the fact that the lead-safe certificate program was targeted at poor and minority census tracts caused lead levels to fall faster among disadvantaged children than among other children, which likely contributed to the narrowing of both blood lead level and test scores gaps between white, African American, and Hispanic children over this period. 


\section{References}

Ashenfelter, Orley and Alan Krueger (1994) "Estimates of the Economic Return to Schooling from a New Sample of Twins” The American Economic Review, 84(5): 1157-1173.

Bellinger, DC (2005). "Teratogen update: lead and pregnancy".Birth defects research. Part A, Clinical and molecular teratology 73 (6): 409-20.

Bellinger, D. C. (2004) “Lead.” Pediatrics, 113(4 Suppl):1016-22.

Bellinger, D. C. (2008) “Very Low Lead Exposures and Children's Neurodevelopment.” Current Opinion in Pediatrics,20(2):172-77.

Bellinger DC (2008) "Neurological and behavioral consequences of childhood lead exposure” PlosMedicine.5(5):e115-e117.

Berney, B. (1993) "Round and round it goes: The epidemiology of childhood lead poisoning, 1950-1990.” The Milbank Quarterly. 71:3-39.

Billings, Stephen and Kevin Schnepel (2015) “Life Unleaded: Effects of Early Interventions for Children Exposed to Lead” unpublished mimeo.

Brooks-Gunn, J., Klebanov, P. K., Smith, J., Duncan, G. J., \& Lee, K. (2003). The Black-White test score gap in young children: Contributions of test and family characteristics. Applied Developmental Science, 7(4), 239-252.

Brown, Phil (1995) “Race, Class, and Environmental Health: A Review and Systematization of the Literature.” Environmental Research,69(1): 15-30

Brulle, Robert J. and David N. Pellow (2007) Environmental Justice: Human Health and Environmental Inequalities Annu. Rev. Public Health. 27:103-24

Burda, Martin and Matthew Harding (2014) "Environmental Justice: Evidence from Superfund Cleanup durations” Journal of economic behavior and organization 107: 380-401.

Canfield, RL, Henderson CR, Cory-slechta DA, Cox C, Jusko TA and BP Lanphear (2003) "Intellectual impairment in children with blood lead concentrations below 10 microg per deciliter” new England Journal of Medicine, 248(16):1517-26.

Chandramouli, K, Steer CD, Eillis M, and AM Emond (2009) "Effects of learly childhood lead exposure on acadmici performance and behavior of school aged children” Arch Dis Child 94:844-848.

Chay, Kenneth, Guryan, Jonathan and Bhashkar Mazumder (2009) "Birth Cohort and the BlackWhite Achievement Gap: The Roles of Access and Health Soon After Birth” NBER WP 15078. 
Chay, Kenneth and Michael Greenstone (2005) "Does air quality matter? Evidence from the housing market” Journal of Political Economy 113(2):376-424.

Cook, M. D., \& Evans, W. N. (2000). "Families or schools? Explaining the convergence in white and black academic performance. “ Journal of labor Economics, 18(4), 729-754.

Chalfin, Aaron and Justin McCrary (forthcoming) “Are US Cities Underpoliced? Theory and Evidence” Review of Economics and Statistics

Card, David and Jesse Rothstein (2007) "Racial Segregation and the Black-White Test Score Gap.” Journal of Public Economics 91, 11-12: 2158-2184

Currie, Janet. (2011) “Inequality at Birth: Some Causes and Consequences,” American Economic Review, 101(3): 1-22.

Currie, Janet, Davis, Lucas, Greenstone, Michael and Reed Walker (2015) "Environmental Health Risks and Housing Values: Evidence from 1600 Toxic Plant Openings and Closings,” American Economic Review, 105(2):678-709.

CDC MMR Weekly "Blood Lead Levels in Children Aged 1-5 Years — United States, 19992010 April 5, 2013 / 62(13);245-248

Dart, R.C., Hurlbut, K.M., Boyer-Hassen, L.V. (2004). "Lead". In Dart, RC. Medical Toxicology (3rd ed.). Lippincott Williams \& Wilkins.

Dee, T. S. (2005). A teacher like me: Does race, ethnicity, or gender matter?American Economic Review, 158-165.

Dee, Thomas and Brian Jacob. "The Impact of NCLB on Students, Teachers, and Schools," Brookings Papers on Economic Activity, Fall 2010, 2007-2013.

Ewart, Stephanie. “The Decline in Private School Enrollment” SEHSD Working Paper Number FY12- 117 January, 2013, U.S. Census Bureau Social, Economic, and Housing Statistics Division

Ferrie, Joseph, Rolf, Karen and Werner Troesken (2014) “Attainment, Income and Longevity: Differential Impact of Childhood Household Socioeconomic Status and the Perpetual Disadvantage Across Generations, 1890-2010”

Ferrie, Joseph, Rolf, Karen and Werner Troesken (2012) “Cognitive disparities, lead plumbing, and water chemistry: prior exposure to water-borne lead and intelligence test scores among World War Two U.S. Army enlistees.” Econ Hum Biol. 10(1):98-111.

Figlio, D. N. (2005). Names, expectations and the black-white test score gap (No. w11195). National Bureau of Economic Research. 
Filippelli, GM, Laidlaw, MAS, Latimer, JC and R Raftis (2005) Geological Society of American Today, 15(1):4-11.

Finkelstein, Y, Markowtiz, ME and JF Rosen (1998) "Low level lead-induced neurotoxicity in children: an update on central nervous system effects’ Brain Research Review 27(2):168-176.

Fryer Jr, R. G., \& Levitt, S. D. (2004). Understanding the black-white test score gap in the first two years of school. Review of Economics and Statistics, 86(2), 447-464.

Griliches, Zvi and Jerry Hausmn. (1986). “Errors in Variables in Panel Data.” Journal of Econometrics. 31:93-118.

Grönqvist, Hans, Nilsson, Peter and Per-Olof Robling, (2014) "Early-childhood Lead Exposure and Criminal Behavior: Lessons from the Swedish Phase-out of Leaded Gasoline” SOFI working paper 2014/9, Stockholm University.

Guilarte, Tomás R., Toscano, Christopher D., McGlothan, Jennifer L. and Shelley Weaver (2002) "Environmental enrichment reverses cognitive and molecular deficits induced by developmental lead exposure.” Annals of Neurology, 53(1):50-56.

Hanushek, E. A., \& Rivkin, S. G. (2006). School quality and the black-white achievement gap (No. w12651). National Bureau of Economic Research.

Hanushek, E. A. (2001). Black-white achievement differences and governmental interventions. American Economic Review, 24-28.

Jencks, Christopher and Meredith Phillips, eds. (2008) The Black-White Test Score Gap.

Washington DC: Brookings Institution Press.

Johnson, William R., and Derek Neal (1998). Basic skills and the black-white earnings gap. The Black-White test score gap, 480-497.

Jones, Robert, Homa, David, Meyers, Pamela, Brody, Debra, Caldwell, Kathleen, Pirkle, James and Mary Jean Brown (2009) "Trends in Blood Lead Levels and Blood Lead Testing Among US Children aged 1 to 5 Year, 1988-2004” Pediatrics 123(3): E376-85.

Krueger, Alan. (2003) “Economic Considerations and Class Size,” The Economic Journal, 113 (February), F34-F63.

Krueger, A. B., \& Whitmore, D. M. (2001). Would smaller classes help close the black-white achievement gap? (No. 451). Industrial Relations Section, Princeton University. 
Lang, Kevin. Poverty and Discrimination, Princeton University Press: Princeton NJ, 2006.

Lanphear, Bruce P., Richard Hornung, Jane Khoury, Kimberly Yolton, Peter Baghurst, David C. Bellinger, Richard L. Canfield, et al. (2005). "Low-level environmental lead exposure and children's intellectual function: an international pooled analysis.” Environmental Health Perspectives 113(7): 894-899.

Levin, R., Brown, M. J., Kashtock, M. E., Jacobs, D. E., Whelan, E. A., Rodman, J., ... Sinks, T. (2008). Lead Exposures in U.S. Children, 2008: Implications for Prevention. Environmental Health Perspectives, 116(10), 1285-1293

Lidsky, Theodore and Jay Schneider (2003) "Lead neurotoxicity in children: basic mechanisms and clinical correlates” Brain: A Journal of Neurology. 126:5-19.

McLaine, Pat, Navas-Acien, Ana, Lee, Rebecca, Simon, Peter, Diener-West, Marie and Jacqueline Agnew (2013) "Elevated Blood Lead Levels and Reading Readiness at the Start of Kindergarten” Pediatrics, 131(6):1081-1089.

Magnuson, Katherine and Jane Waldfogel, eds. (2008) Steady Gains and Stalled Progress: Inequality and the Black-White Test Score Gap. New York: Russell Sage Press.

Masters, Roger D, Hone, Brian and Anil Dosh (1998) "Environmental pollution, Neurotoxicity, and Criminal Violence” in J. Rose., ed., Environmental Toxicology: Current

Developments (London: Taylor and Francis, 1998), pp. 13-48.

Mielke, H. W., and S. Zahran. (2012) "The Urban Rise and Fall of Air Lead (Pb) and the Latent Surge and Retreat of Societal Violence.” Environment International, 43: 48-55.

Mohai, Paul and Robin Saha (2006) "Reassessing racial and socioeconomic disparities in environmental justice research” Demography 43(2):383-399.

Nevin, R..(2007) "Understanding International Crime Trends: The Legacy of Preschool Lead Exposure.” Environmental Research, 104(3): 315-36.

Nigg, Joel, Nikolas, Molly, Knottnerus, Mark, Cavanagh, Kevin and Karen Friderici (2010) "Confirmation and extension of association of blood lead with attention definit/hyperactivity disorder (ADHD) and ADHS symptom domains at population-typical exposure levels" Journal Child Psychology and Psychiatria, 51(1):58-65.

O’Neil SG (2007) “Superfund: evaluating the impact of executive order 12898.” Environ Health Perspec, 115:1087-1093.

Rau, T, Reyes, L and S. Urzua (2015) "Early Exposure to Hazardous Waste and Academic Achievement: Evidence from a Case of Environmental Negligence,” Journal of the Association of Environmental and Resource Economists, 2: 527-563 
Reber, Sarah (2010) School desegregation and the educational attainment for blacks. Journal of Human Resources, 45 (4):893-914.

Reyes, Jessica Wolpaw (2015) "Lead Exposure and Behavior: Effects on Aggression and Risky Behavior among Children and Adolescents,” Economic Inquiry, 53:3.

Reyes, Jessica Wolpaw (2015) "Lead Policy and Academic Performance: Insights from Massachusetts,” Harvard Educational Review, 85(1).

Ringquist, Evan (2005) “Assessing evidence of environmental inequities: a meta-analysis” Journal of Policy Analysis and Management 24(2): 223-247.

Rogers, Michelle, Lucht, James A., Sylvaria, Alyssa, Cigna, Jessica, Vanderslice, Robert and Patrick M. Vivier. (2014) "Primary Prevention of Lead Poisoning: Protecting Children From Unsafe Housing.” American Journal of Public Health. 104(8): e119-e124.

RI Dept of Health (2002) "Lead Poisoning in Rhode Island: The Numbers (2002). Providence, RI: Rhode Island.

US Dept of Education NAEP 2012 Trends in Academic Progress NCES 2013-456.

U.S. Environmental Protection Agency, "Lead and a Healthy Diet: What You Can Do to Protect Your Child,” 2015, www2.epa.gov/sites/production/files/documents/nutrition.pdf.

Vivier, Patrick, Hauptman, M, Weitzen, SH, Bell, S, Quilliam, DN and JR Logan (2011) “The important health impact of where a child lives: neighborhood characteristics and the burden of lead poisoning” Journal of Maternal and Child Health, 15(8):1195-1202. 


\begin{tabular}{|c|c|c|c|c|c|c|c|}
\hline \multicolumn{8}{|c|}{ Table 1: Summary Statistics for Sample } \\
\hline & & & White/Asian/ & & & Never Free & Always \\
\hline & All & White & Other & Black & Hispanic & Lunch & Free Lunch \\
\hline \multicolumn{8}{|l|}{ Preschool Lead Levels } \\
\hline \# of tests & 2.7 & 2.5 & 2.5 & 3.1 & 3.3 & 2.4 & 3.2 \\
\hline \# of venous tests & 1.9 & 1.5 & 1.6 & 2.4 & 2.8 & 1.4 & 2.5 \\
\hline Lead (geometric mean) & 3.12 & 2.80 & 2.80 & 4.20 & 3.60 & 2.40 & 3.90 \\
\hline Share geom. mean >=5 & 0.17 & 0.14 & 0.14 & 0.30 & 0.23 & 0.09 & 0.27 \\
\hline Share geom. mean $>=10$ & 0.02 & 0.01 & 0.01 & 0.05 & 0.03 & 0.01 & 0.04 \\
\hline Share any $B L L>=5$ & 0.40 & 0.33 & 0.34 & 0.57 & 0.54 & 0.26 & 0.57 \\
\hline Share any $B L L>=10$ & 0.09 & 0.06 & 0.06 & 0.17 & 0.13 & 0.03 & 0.15 \\
\hline \multicolumn{8}{|l|}{ Test scores } \\
\hline Third grade reading & 45.5 & 48.1 & 47.90 & 40.6 & 39.2 & 50.8 & 39.7 \\
\hline Not reading proficient & 0.12 & 0.08 & 0.08 & 0.19 & 0.22 & 0.04 & 0.21 \\
\hline Third grade math & 42.2 & 44.8 & 44.6 & 36.3 & 36.1 & 47.2 & 36.5 \\
\hline Not math proficient & 0.16 & 0.10 & 0.11 & 0.29 & 0.29 & 0.06 & 0.28 \\
\hline \multicolumn{8}{|l|}{ Lead certificates } \\
\hline Ever Certificate in Home & 0.17 & 0.10 & 0.10 & 0.31 & 0.35 & 0.05 & 0.32 \\
\hline Certificate in home at birth & 0.03 & 0.003 & 0.01 & 0.08 & 0.08 & 0.003 & 0.08 \\
\hline \multicolumn{8}{|l|}{ Characteristics at Birth } \\
\hline Birth Weight (kg) & 3.30 & 3.40 & 3.40 & 3.30 & 3.30 & 3.40 & 3.30 \\
\hline Mother < High School & 0.15 & 0.08 & 0.09 & 0.24 & 0.33 & 0.02 & 0.33 \\
\hline Mother High School & 0.30 & 0.29 & 0.29 & 0.34 & 0.29 & 0.21 & 0.34 \\
\hline Mother College & 0.26 & 0.35 & 0.33 & 0.09 & 0.06 & 0.48 & 0.05 \\
\hline Male & 0.51 & 0.51 & 0.51 & 0.51 & 0.51 & 0.51 & 0.50 \\
\hline Number of Observations & 70678 & 47668 & 50037 & 6967 & 13674 & 30970 & 19060 \\
\hline
\end{tabular}


Table 2: Lead Levels and Test Score Results Over Time, by Group

\begin{tabular}{|c|c|c|c|c|c|c|c|c|c|c|c|c|}
\hline & \multicolumn{2}{|c|}{ Geometric Mean Lead Levels } & \multicolumn{2}{|c|}{ Certificate at Birth } & \multicolumn{2}{|c|}{ Mean Third Grade Reading } & \multicolumn{2}{|c|}{ Not Reading Proficient } & \multicolumn{2}{|c|}{ Mean Third Grade Math } & \multicolumn{2}{|c|}{ Not Math Proficient } \\
\hline & 1997 & 2005 & 1997 & 2005 & 1997 & 2005 & 1997 & 2005 & 1997 & 2005 & 1997 & 2005 \\
\hline \multicolumn{13}{|l|}{ Child Characteristic } \\
\hline \multicolumn{13}{|l|}{ Race } \\
\hline White & 3.49 & 2.02 & 0.00 & 0.02 & 46.20 & 49.30 & 0.10 & 0.07 & 43.00 & 44.40 & 0.12 & 0.11 \\
\hline White/Asian/Other & 3.54 & 2.07 & 0.00 & 0.02 & 46.10 & 48.80 & 0.10 & 0.08 & 42.90 & 44.00 & 0.13 & 0.12 \\
\hline Black & 5.77 & 2.95 & 0.02 & 0.12 & 37.80 & 41.54 & 0.23 & 0.17 & 34.60 & 36.20 & 0.31 & 0.29 \\
\hline Hispanic & 4.91 & 2.52 & 0.01 & 0.13 & 36.20 & 40.47 & 0.30 & 0.21 & 33.90 & 36.40 & 0.35 & 0.29 \\
\hline Asian & 4.42 & 2.64 & 0.02 & 0.09 & 44.40 & 47.40 & 0.09 & 0.07 & 40.50 & 42.20 & 0.21 & 0.14 \\
\hline \multicolumn{13}{|l|}{ Free Lunch } \\
\hline Always Free Lunch & 5.25 & 2.85 & 0.02 & 0.11 & 36.75 & 40.87 & 0.27 & 0.18 & 34.58 & 36.24 & 0.33 & 0.28 \\
\hline Sometimes Free Lunch & 4.32 & 2.38 & 0.01 & 0.07 & 41.25 & 43.49 & 0.17 & 0.17 & 38.53 & 39.26 & 0.21 & 0.22 \\
\hline Never Free Lunch & 3.04 & 1.79 & 0.00 & 0.01 & 48.94 & 51.84 & 0.06 & 0.04 & 45.32 & 46.66 & 0.08 & 0.07 \\
\hline \multicolumn{13}{|l|}{ Maternal Education } \\
\hline$>=\mathrm{HS}$ & 3.73 & 2.18 & 0.01 & 0.04 & 45.03 & 48.73 & 0.12 & 0.09 & 41.88 & 42.84 & 0.15 & 0.14 \\
\hline$<\mathrm{HS}$ & 5.12 & 2.82 & 0.01 & 0.12 & 36.67 & 38.27 & 0.28 & 0.27 & 34.51 & 34.00 & 0.35 & 0.37 \\
\hline \multicolumn{13}{|l|}{ Marital Status at birth } \\
\hline Single & 4.87 & 2.68 & 0.01 & 0.11 & 38.79 & 41.93 & 0.22 & 0.18 & 36.22 & 37.23 & 0.28 & 0.26 \\
\hline Married & 3.55 & 2.05 & 0.00 & 0.03 & 45.87 & 48.87 & 0.11 & 0.08 & 42.68 & 44.01 & 0.14 & 0.12 \\
\hline
\end{tabular}

Note: Because only data through August is available for birth cohort 2005, the sample used in this table includes all children born between January and August of the respective years. 


\begin{tabular}{|c|c|c|c|c|c|}
\hline \multicolumn{6}{|c|}{ Table 3a: OLS \& FE Estimates: Pre-School Lead and Third Grade Reading Scores } \\
\hline & $(1)$ & $(2)$ & (3) & $(4)$ & $(5)$ \\
\hline & OLS & OLS & Tract FE & Tract FE & Tract FE \\
\hline \multirow[t]{2}{*}{ Geometric Mean of Lead } & -0.456 & -0.326 & -0.335 & -0.305 & -0.326 \\
\hline & [0.0196] & [0.0196] & [0.0199] & [0.0197] & [0.0199] \\
\hline \multirow{2}{*}{$\begin{array}{l}\text { Avg. 3rd grade reading score in } \\
\text { school*grade }\end{array}$} & & & & 0.439 & \\
\hline & & & & [0.0114] & \\
\hline \multirow[t]{2}{*}{ Tract 1997 Reading Score*Year } & & & & & -0.0252 \\
\hline & & & & & [0.00370] \\
\hline \multirow[t]{2}{*}{ African American } & 1.029 & 1.580 & 1.618 & 1.832 & 1.748 \\
\hline & [0.925] & [0.912] & [0.911] & [0.901] & [0.911] \\
\hline \multirow[t]{2}{*}{ White } & 3.910 & 3.210 & 3.263 & 2.760 & 3.420 \\
\hline & [0.919] & [0.907] & [0.906] & [0.896] & [0.906] \\
\hline \multirow[t]{2}{*}{ Hispanic } & -0.178 & 0.777 & 0.795 & 1.165 & 0.966 \\
\hline & [0.921] & [0.907] & [0.906] & [0.896] & [0.906] \\
\hline \multirow[t]{2}{*}{ Asian } & 4.276 & 4.915 & 4.980 & 4.868 & 5.140 \\
\hline & [0.948] & [0.934] & [0.933] & [0.923] & [0.933] \\
\hline \multirow[t]{2}{*}{ Always free/reduced lunch } & -8.224 & -4.806 & -4.687 & -3.802 & -4.705 \\
\hline & [0.131] & [0.150] & [0.152] & [0.152] & [0.152] \\
\hline \multirow[t]{2}{*}{ Sometimes free/reduced lunch } & -6.163 & -3.759 & -3.664 & -3.197 & -3.653 \\
\hline & [0.111] & [0.123] & [0.124] & [0.123] & [0.124] \\
\hline \multirow[t]{2}{*}{ Male } & -3.162 & -3.333 & -3.320 & -3.278 & -3.323 \\
\hline & [0.0868] & [0.0857] & [0.0855] & [0.0846] & [0.0855] \\
\hline \multirow[t]{2}{*}{ Birth weight in kg } & & 1.195 & 1.179 & 1.156 & 1.176 \\
\hline & & [0.0792] & [0.0791] & [0.0783] & [0.0791] \\
\hline \multirow[t]{2}{*}{ Mother <HS } & & -3.590 & -3.546 & -3.200 & -3.550 \\
\hline & & [0.184] & [0.185] & [0.183] & [0.184] \\
\hline \multirow[t]{2}{*}{ Mother HS grad } & & -1.475 & -1.444 & -1.345 & -1.450 \\
\hline & & [0.154] & [0.153] & [0.152] & [0.153] \\
\hline \multirow[t]{2}{*}{ Mother College+ } & & 1.750 & 1.664 & 1.565 & 1.676 \\
\hline & & [0.157] & [0.158] & [0.156] & [0.158] \\
\hline \multirow[t]{2}{*}{ Married at birth } & & 0.521 & 0.531 & 0.462 & 0.531 \\
\hline & & [0.118] & [0.118] & [0.117] & [0.118] \\
\hline \multirow[t]{2}{*}{ Birth order } & & -0.670 & -0.671 & -0.639 & -0.671 \\
\hline & & [0.0455] & [0.0455] & [0.0450] & [0.0454] \\
\hline \multirow[t]{2}{*}{ Birth weight missing- imputed } & & 0.721 & 0.703 & 0.616 & 0.739 \\
\hline & & [0.272] & [0.273] & [0.270] & [0.273] \\
\hline \multirow[t]{2}{*}{ Maternal education -imputed } & & -1.588 & -1.624 & -1.386 & -1.631 \\
\hline & & [0.277] & [0.277] & [0.274] & [0.277] \\
\hline \multirow[t]{2}{*}{ Families: Income in 2012 below poverty } & & -0.947 & 2.755 & 3.449 & 4.896 \\
\hline & & [0.728] & [4.788] & [4.737] & [4.798] \\
\hline \multirow[t]{2}{*}{ Median Family Income (In \$1000 2010) } & & 0.054 & 0.053 & $-3.31 e-05$ & $1.29 \mathrm{e}-05$ \\
\hline & & [0.0034] & [0.0279] & [2.76e-05] & [2.96e-05] \\
\hline \multirow[t]{2}{*}{ Share of housing built post 1978} & & -2.900 & 4.783 & 2.794 & 11.14 \\
\hline & & {$[0.369]$} & {$[3.384]$} & {$[3.347]$} & {$[3.508]$} \\
\hline Observations & 70,678 & 70,678 & 70,678 & 70,635 & 70,658 \\
\hline R-squared & 0.187 & 0.215 & 0.107 & 0.125 & 0.107 \\
\hline Number of FE & & & 233 & 233 & 230 \\
\hline
\end{tabular}

Standard errors in brackets. All regressions also include year and month of birth FE. 


\begin{tabular}{|c|c|c|c|c|c|}
\hline \multicolumn{6}{|c|}{ Table 3b: OLS \& FE Estimates: Pre-School Lead and Third Grade Math Scores } \\
\hline & $(1)$ & $(2)$ & (3) & (4) & $(5)$ \\
\hline & OLS & OLS & Tract FE & Tract FE & Tract FE \\
\hline \multirow[t]{2}{*}{ Geometric Mean of Lead } & -0.348 & -0.216 & -0.220 & -0.189 & -0.210 \\
\hline & [0.0185] & [0.0185] & [0.0187] & [0.0183] & [0.0187] \\
\hline \multirow{2}{*}{$\begin{array}{l}\text { Average third grade math score for } \\
\text { school*grade }\end{array}$} & & & & 0.516 & \\
\hline & & & & [0.0105] & \\
\hline \multirow[t]{2}{*}{ Tract 1997 Math Score*Year } & & & & & -0.0294 \\
\hline & & & & & {$[0.00375]$} \\
\hline \multirow[t]{2}{*}{ African American } & 0.605 & 1.198 & 1.181 & 1.425 & 1.326 \\
\hline & {$[0.873]$} & {$[0.858]$} & [0.855] & {$[0.840]$} & {$[0.855]$} \\
\hline \multirow[t]{2}{*}{ White } & 4.764 & 4.049 & 3.824 & 3.218 & 3.997 \\
\hline & {$[0.867]$} & [0.853] & {$[0.851]$} & {$[0.836]$} & [0.851] \\
\hline \multirow[t]{2}{*}{ Hispanic } & 0.550 & 1.507 & 1.533 & 1.889 & 1.718 \\
\hline & {$[0.869]$} & {$[0.854]$} & {$[0.851]$} & {$[0.836]$} & [0.851] \\
\hline \multirow[t]{2}{*}{ Asian } & 4.788 & 5.434 & 5.555 & 5.458 & 5.731 \\
\hline & [0.894] & {$[0.878]$} & {$[0.876]$} & {$[0.861]$} & {$[0.876]$} \\
\hline \multirow[t]{2}{*}{ Always free/reduced lunch } & -7.632 & -4.152 & -4.136 & -3.194 & -4.154 \\
\hline & {$[0.123]$} & {$[0.142]$} & {$[0.142]$} & {$[0.141]$} & {$[0.142]$} \\
\hline \multirow[t]{2}{*}{ Sometimes free/reduced lunch } & -5.992 & -3.465 & -3.410 & -2.911 & -3.401 \\
\hline & {$[0.105]$} & {$[0.116]$} & {$[0.117]$} & {$[0.115]$} & {$[0.117]$} \\
\hline \multirow[t]{2}{*}{ Male } & 0.0668 & -0.132 & -0.123 & -0.0825 & -0.129 \\
\hline & {$[0.0819]$} & {$[0.0806]$} & {$[0.0804]$} & {$[0.0790]$} & {$[0.0803]$} \\
\hline \multirow[t]{2}{*}{ Birth weight in kg } & & 1.501 & 1.489 & 1.483 & 1.487 \\
\hline & & {$[0.0745]$} & {$[0.0743]$} & {$[0.0730]$} & {$[0.0743]$} \\
\hline \multirow[t]{2}{*}{ Mother < HS } & & -3.196 & -3.214 & -2.805 & -3.220 \\
\hline & & {$[0.174]$} & {$[0.173]$} & {$[0.171]$} & {$[0.173]$} \\
\hline \multirow[t]{2}{*}{ Mother HS grad } & & -1.300 & -1.320 & -1.190 & -1.326 \\
\hline & & [0.145] & [0.144] & {$[0.142]$} & [0.144] \\
\hline \multirow[t]{2}{*}{ Mother College+ } & & 1.931 & 1.851 & 1.705 & 1.859 \\
\hline & & [0.148] & [0.148] & {$[0.145]$} & {$[0.148]$} \\
\hline \multirow[t]{2}{*}{ Married at birth } & & 0.706 & 0.764 & 0.679 & 0.763 \\
\hline & & {$[0.111]$} & [0.111] & [0.109] & [0.111] \\
\hline \multirow[t]{2}{*}{ Birth order } & & -0.403 & -0.418 & -0.383 & -0.420 \\
\hline & & [0.0428] & [0.0427] & {$[0.0420]$} & [0.0427] \\
\hline \multirow[t]{2}{*}{ Birth weight missing- imputed } & & 0.637 & 0.450 & 0.352 & 0.484 \\
\hline & & {$[0.256]$} & {$[0.256]$} & {$[0.252]$} & {$[0.256]$} \\
\hline \multirow[t]{2}{*}{ Maternal education - imputed } & & -1.344 & -1.405 & -1.134 & -1.409 \\
\hline & & {$[0.260]$} & {$[0.260]$} & {$[0.255]$} & {$[0.260]$} \\
\hline \multirow[t]{2}{*}{ Families: Income in 2012 below poverty } & & -0.257 & 6.687 & 7.118 & 8.855 \\
\hline & & [0.685] & [4.499] & [4.421] & {$[4.506]$} \\
\hline \multirow[t]{2}{*}{ Median Family Income (In \$1000 2010) } & & 0.058 & -0.030 & $-1.78 e-05$ & $5.26 \mathrm{e}-05$ \\
\hline & & [0.0032] & [0.0262] & {$[2.58 \mathrm{e}-05]$} & {$[2.83 e-05]$} \\
\hline \multirow[t]{2}{*}{ Share of housing built post 1978} & & -1.753 & 8.404 & 4.787 & 15.13 \\
\hline & & {$[0.347]$} & {$[3.178]$} & {$[3.124]$} & {$[3.290]$} \\
\hline Observations & 70,625 & 70,625 & 70,625 & 70,582 & 70,605 \\
\hline R-squared & 0.181 & 0.213 & 0.091 & 0.121 & 0.092 \\
\hline Number of FE & & & 233 & 233 & 230 \\
\hline
\end{tabular}

Standard errors in brackets. All regressions also include year and month of birth FE. 


\section{Table 4: Exploring Effects of Measurement Error in Lead Levels on Estimated Effects on Test Scores Using Venous Tests as IV for Capillary Tests, and Using Average of All Tests as IV for a Random Draw}

\begin{tabular}{|c|c|c|c|c|c|c|}
\hline \multicolumn{7}{|l|}{ A: Reading Scores } \\
\hline & (1) & $(2)$ & (3) & (4) & (5) & (6) \\
\hline & $\mathrm{FE}$ & $\mathrm{FE}$ & FE-IV & $\mathrm{FE}$ & $\mathrm{FE}$ & FE-IV \\
\hline \multirow[t]{2}{*}{ Average of all capillary tests } & -0.142 & & -0.537 & & & \\
\hline & [0.0293] & & [0.0639] & & & \\
\hline \multirow[t]{2}{*}{ Average of all venous tests } & & -0.315 & & & & \\
\hline & & {$[0.0371]$} & & & & \\
\hline \multirow[t]{2}{*}{ First random draw } & & & & -0.201 & & -0.454 \\
\hline & & & & {$[0.0156]$} & & {$[0.0306]$} \\
\hline \multirow[t]{2}{*}{ Avg all other tests } & & & & & -0.284 & \\
\hline & & & & & {$[0.0191]$} & \\
\hline Observations & 12,012 & 12,012 & 12,012 & 54,491 & 54,491 & 54,491 \\
\hline R-squared & 0.116 & 0.120 & & 0.111 & 0.112 & \\
\hline Instrument: & & & $\begin{array}{c}\text { venous } \\
\text { tests }\end{array}$ & & & $\begin{array}{l}\text { other } \\
\text { tests }\end{array}$ \\
\hline \multicolumn{7}{|l|}{ B: Math Scores } \\
\hline & (1) & $(2)$ & (3) & (4) & (5) & (6) \\
\hline & $\mathrm{FE}$ & FE & FE-IV & $\mathrm{FE}$ & $\mathrm{FE}$ & FE-IV \\
\hline \multirow[t]{2}{*}{ Average of all capillary tests } & -0.102 & & -0.343 & & & \\
\hline & [0.0277] & & [0.0600] & & & \\
\hline \multirow[t]{2}{*}{ Average of all venous tests } & & -0.201 & & & & \\
\hline & & {$[0.0351]$} & & & & \\
\hline \multirow[t]{2}{*}{ First random draw } & & & & -0.133 & & -0.308 \\
\hline & & & & {$[0.0146]$} & & [0.0287] \\
\hline \multirow[t]{2}{*}{ Avg all other tests } & & & & & -0.193 & \\
\hline & & & & & {$[0.0180]$} & \\
\hline Observations & 12,002 & 12,002 & 12,002 & 54,449 & 54,449 & 54,449 \\
\hline R-squared & 0.101 & 0.103 & & 0.093 & 0.094 & \\
\hline Instrument: & & & $\begin{array}{c}\text { venous } \\
\text { tests }\end{array}$ & & & $\begin{array}{l}\text { other } \\
\text { tests }\end{array}$ \\
\hline
\end{tabular}

Specification is the same as column 3 of Tables $3 a$ and $3 b$ so that all models include Census tract fixed effects as well as year and month of birth fixed effects and the other covariates listed in Table 3. 


\begin{tabular}{|c|c|c|c|}
\hline & (1) & (2) & (3) \\
\hline \multirow[t]{2}{*}{ Certificates in tract at birth } & 0.898 & 0.469 & \\
\hline & {$[0.0544]$} & [0.0615] & \\
\hline \multirow[t]{2}{*}{ Certificates in tract at birth squared } & -1.400 & -1.276 & \\
\hline & {$[0.136]$} & [0.137] & \\
\hline \multirow[t]{2}{*}{ Certificates*free lunch } & & 0.264 & \\
\hline & & [0.0374] & \\
\hline \multirow[t]{2}{*}{ Certificates*black } & & 0.292 & \\
\hline & & {$[0.0386]$} & \\
\hline \multirow[t]{2}{*}{ Certificates*Hispanic } & & 0.297 & \\
\hline & & [0.0329] & \\
\hline \multirow[t]{2}{*}{ HRC Certificates at birth } & & & 0.707 \\
\hline & & & {$[0.0706]$} \\
\hline \multirow[t]{2}{*}{ HRC Certificates at birth squared } & & & -1.178 \\
\hline & & & [0.288] \\
\hline \multirow[t]{2}{*}{ DOH Certificates at birth } & & & 1.166 \\
\hline & & & [0.0911] \\
\hline \multirow[t]{2}{*}{ DOH Certificates at birth squared } & & & -2.528 \\
\hline & & & [0.214] \\
\hline \multirow[t]{2}{*}{ African American } & 0.0153 & -0.00356 & 0.0175 \\
\hline & [0.0131] & [0.0133] & [0.0131] \\
\hline \multirow[t]{2}{*}{ White } & 0.00305 & -0.00599 & 0.00570 \\
\hline & {$[0.0130]$} & {$[0.0130]$} & [0.0130] \\
\hline \multirow[t]{2}{*}{ Hispanic } & 0.00997 & -0.00977 & 0.0128 \\
\hline & {$[0.0130]$} & [0.0132] & {$[0.0130]$} \\
\hline \multirow[t]{2}{*}{ Asian } & 0.000413 & -0.00419 & 0.00338 \\
\hline & [0.0134] & [0.0134] & [0.0134] \\
\hline \multirow[t]{2}{*}{ Always free/reduced lunch } & 0.00627 & 0.00137 & 0.00627 \\
\hline & [0.00217] & [0.00228] & [0.00217] \\
\hline \multirow[t]{2}{*}{ Sometimes free/reduced lunch } & -0.00278 & -0.00662 & -0.00277 \\
\hline & {$[0.00178]$} & {$[0.00187]$} & [0.00178] \\
\hline \multirow[t]{2}{*}{ Male } & -0.000470 & -0.000508 & -0.000487 \\
\hline & [0.00123] & [0.00122] & {$[0.00122]$} \\
\hline \multirow[t]{2}{*}{ Birth weight in $\mathrm{kg}$} & $3.15 e-05$ & $-9.31 e-05$ & $2.27 e-05$ \\
\hline & [0.00113] & [0.00113] & [0.00113] \\
\hline \multirow[t]{2}{*}{ Mother < HS } & 0.00566 & 0.00551 & 0.00556 \\
\hline & [0.00264] & {$[0.00264]$} & [0.00264] \\
\hline Mother HS grad & -0.000103 & -0.000193 & -0.000114 \\
\hline & {$[0.00220]$} & [0.00220] & {$[0.00220]$} \\
\hline Mother College+ & -0.00122 & -0.00118 & -0.00118 \\
\hline & [0.00226] & [0.00226] & {$[0.00226]$} \\
\hline Married at birth & -0.00910 & -0.00923 & -0.00917 \\
\hline & [0.00169] & [0.00169] & [0.00169] \\
\hline Birth order & 0.00181 & 0.00186 & 0.00180 \\
\hline & [0.000651] & [0.000650] & {$[0.000650]$} \\
\hline Birth weight missing- imputed & -0.0168 & -0.0156 & -0.0160 \\
\hline & [0.00391] & [0.00391] & [0.00391] \\
\hline Maternal education - imputed & 0.00999 & 0.00937 & 0.00946 \\
\hline & [0.00397] & [0.00396] & [0.00396] \\
\hline Families: Income in 2012 below poverty & -0.00255 & 0.0229 & 0.0788 \\
\hline & {$[0.0687]$} & {$[0.0686]$} & {$[0.0692]$} \\
\hline Median Family Income (In \$1000 2010) & $-1.07 e-06$ & $-1.05 e-06$ & $-9.26 e-07$ \\
\hline & [4.08e-07] & [4.08e-07] & [4.08e-07] \\
\hline Share of housing built post 1978 & -0.340 & -0.243 & -0.304 \\
\hline & {$[0.0486]$} & [0.0489] & [0.0486] \\
\hline Home ever had a certificate & 0.105 & 0.105 & 0.105 \\
\hline & [0.00177] & [0.00177] & [0.00177] \\
\hline Observations & 70,678 & 70,678 & 70,678 \\
\hline R-squared & 0.070 & 0.073 & 0.071 \\
\hline
\end{tabular}

Standard errors in brackets. All regressions also include census tract, year and month of birth FE. 


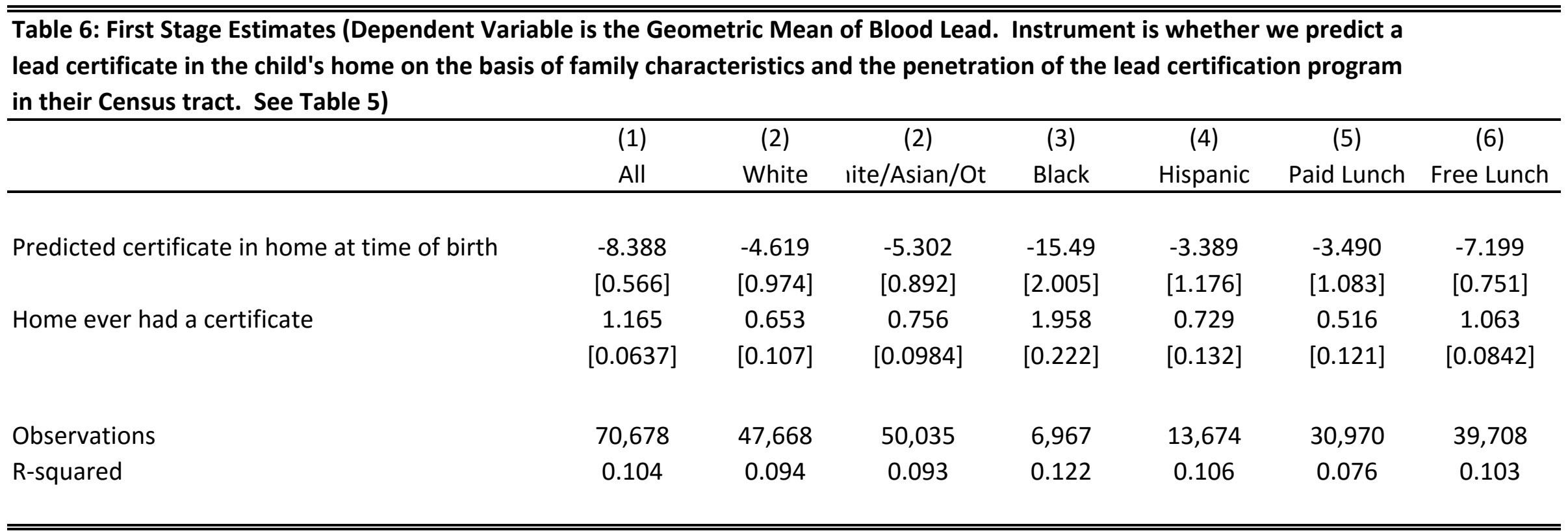

Predicted certificates are based on the model in column 2 of Table 5.

Models include all of the variables listed in Table 5 including census tract, year of birth and month of birth FE.

Standard errors in brackets. 


\begin{tabular}{|c|c|c|c|}
\hline \multicolumn{4}{|c|}{ Table 7: Census Tract FE and IV Estimates of Effects of Lead on Third Grade Scores } \\
\hline & $(1)$ & $(2)$ & (3) \\
\hline & $\mathrm{FE}$ & FE IV & FE IV \\
\hline \multicolumn{4}{|c|}{ Dependent Variable: Below Proficient in Reading } \\
\hline \multirow[t]{2}{*}{ Geometric Mean of Lead } & 0.0075 & 0.0387 & 0.0308 \\
\hline & [0.0005] & [0.0099] & {$[0.0136]$} \\
\hline Observations & 70,678 & 70,678 & 70,635 \\
\hline R-squared & 0.037 & & \\
\hline \multicolumn{4}{|c|}{ Dependent Variable: Reading Score } \\
\hline \multirow[t]{2}{*}{ Geometric Mean of Lead } & -0.332 & -1.014 & -0.948 \\
\hline & [0.0199] & {$[0.3590]$} & [0.487] \\
\hline Observations & 70,678 & 70,678 & 70,635 \\
\hline R-squared & 0.107 & & \\
\hline \multicolumn{4}{|c|}{ Dependent Variable: Below Proficient in Math } \\
\hline \multirow[t]{2}{*}{ Geometric Mean of Lead } & 0.0056 & 0.0198 & 0.0231 \\
\hline & {$[0.0006]$} & {$[0.0110]$} & [0.0148] \\
\hline Observations & 70,625 & 70,625 & 70,582 \\
\hline R-squared & 0.035 & & \\
\hline \multicolumn{4}{|c|}{ Dependent Variable: Math Score } \\
\hline \multirow[t]{2}{*}{ Geometric Mean of Lead } & -0.217 & 0.0192 & -0.387 \\
\hline & {$[0.0187]$} & {$[0.3350]$} & [0.439] \\
\hline Observations & 70,625 & 70,625 & 70,582 \\
\hline R-squared & 0.091 & & \\
\hline
\end{tabular}

Additional Controls:

Average score in grade*school (leave-out mean)

Percent below proficient in grade*school (leave-out mean)

Race specific linear time trend

Free lunch specific linear time trend

$Y$
$Y$
$Y$
$Y$

Models include all the controls listed in Column 3 of Table 5 including tract, year of birth, and birth month fixed effects. Instrument is whether the child is predicted to have had a lead certificate at the time they were first tested, based on the model shown in column 2 of Table 5 which includes certificates issued in census tract by time of child's birth.

Standard errors are shown in brackets. 
Appendix Table 1: Sample Construction

\begin{tabular}{|c|c|c|c|c|c|c|}
\hline & \multicolumn{3}{|c|}{$\operatorname{RIDE}(n=122,786)$} & \multicolumn{2}{|c|}{ RIDE-Lead (w/test score) $(n=77,777)$} & \multirow[t]{3}{*}{$\begin{array}{c}\text { RIDE w/Test Scores } \\
(n=91,456)\end{array}$} \\
\hline & \multirow[t]{2}{*}{ No Lead $(n=30,795)$} & \multicolumn{2}{|c|}{ Lead $(n=91,991)$} & \multirow[b]{2}{*}{ No VS $(n=12,008)$} & \multirow[b]{2}{*}{ VS $(n=65,769)$} & \\
\hline & & $\begin{array}{c}\text { No Test Score } \\
(n=14,214)\end{array}$ & $\begin{array}{l}\text { Test Score } \\
(n=77,777)\end{array}$ & & & \\
\hline \multicolumn{7}{|l|}{ From RIDE or VS: } \\
\hline Black & 0.15 & 0.1 & 0.1 & 0.11 & 0.09 & 0.1 \\
\hline White & 0.5 & 0.67 & 0.68 & 0.55 & 0.71 & 0.69 \\
\hline Hispanic & 0.23 & 0.19 & 0.19 & 0.27 & 0.17 & 0.19 \\
\hline Asian & 0.06 & 0.04 & 0.03 & 0.05 & 0.03 & 0.03 \\
\hline Never Free Lunch & 0.4 & 0.45 & 0.44 & 0.4 & 0.45 & 0.43 \\
\hline Always Free Lunch & 0.39 & 0.27 & 0.27 & 0.31 & 0.26 & 0.27 \\
\hline \multicolumn{7}{|l|}{ From VS: } \\
\hline Maternal education & & 13.2 & 13.2 & & 13.2 & 13.2 \\
\hline Married at birth & & 0.57 & 0.61 & & 0.61 & 0.61 \\
\hline Maternal age at birth & & 28.1 & 28.6 & & 28.6 & 28.6 \\
\hline Birth Order & & 1.9 & 1.9 & & 1.9 & 1.9 \\
\hline Birth weight & & 3311 & 3341 & & 3341 & 3340 \\
\hline \multicolumn{7}{|l|}{ From RIDOH: } \\
\hline Lead - avg & & 3.1 & 3.1 & 3.25 & 3.1 & 3.1 \\
\hline \multicolumn{3}{|c|}{ Third Grade Reading Scores } & 45.6 & 46.2 & 45.7 & 45.2 \\
\hline
\end{tabular}

Notes: For column 1 (education data but no lead test) we do not present means for vital statistics data because there are few observations with such data. The sample used for analysis is shown in column 3 and includes imputations of some variables drawn from the vital statistics data. Columns 4 and 5 show means for the non-imputed sample. 
Appendix Table 2: Age of Housing and Child Characteristics

Concentration of Children by Race and Income Living in Old Housing in the US and RI

\begin{tabular}{|c|c|c|c|c|c|}
\hline & & \multicolumn{2}{|c|}{ US Share in Housing Built } & \multicolumn{2}{|c|}{ RI Share in Housing Built } \\
\hline & & Pre 1978 & Pre 1945 & Pre 1978 & Pre 1945 \\
\hline Black & & 0.72 & 0.22 & 0.83 & 0.52 \\
\hline White & & 0.63 & 0.22 & 0.74 & 0.37 \\
\hline Hispanic & & 0.68 & 0.2 & 0.83 & 0.53 \\
\hline$<=100 \% \mathrm{FPL}$ & & & & 0.81 & 0.43 \\
\hline$>=200 \% \mathrm{FPL}$ & & & & 0.76 & 0.4 \\
\hline$<200 \%$ FPL and Black & & & & 0.83 & 0.5 \\
\hline$<200 \%$ FPL and White & & & & 0.84 & 0.48 \\
\hline \multicolumn{6}{|l|}{ Black } \\
\hline & 2010 & 0.58 & 0.18 & 0.82 & 0.58 \\
\hline & 2000 & 0.7 & 0.21 & 0.85 & 0.47 \\
\hline & 1990 & 0.81 & 0.26 & 0.82 & 0.52 \\
\hline \multicolumn{6}{|l|}{ White } \\
\hline & 2010 & 0.5 & 0.18 & 0.62 & 0.41 \\
\hline & 2000 & 0.59 & 0.21 & 0.71 & 0.34 \\
\hline & 1990 & 0.73 & 0.25 & 0.8 & 0.32 \\
\hline
\end{tabular}

Concentration of Children by Race and Income Living in Providence

$$
\text { Providence Rest of State }
$$

\begin{tabular}{lcc} 
Share housing built pre 1978 & 0.81 & 0.68 \\
Share housing built pre 1945 & 0.49 & 0.27 \\
& & \\
& 0.86 & 0.14 \\
Share black population living in: & 0.51 & 0.49 \\
Share white population living in: & & \\
& 0.77 & 0.23 \\
Share population <100\% FPL living in: & 0.55 & 0.45 \\
Share population >100\% FPL lining in: & & \\
& & 0.11 \\
Share population <100\% FPL \& black livin & 0.89 & 0.4 \\
\hline Share population <100\% FPL \& white livir & 0.6 &
\end{tabular}

Calculations from US census IPUMS data for 1990, 2000 and 2010

Sample includes all children $<=10$ years old 
Figure 1: Lead Certificates by Census Tract

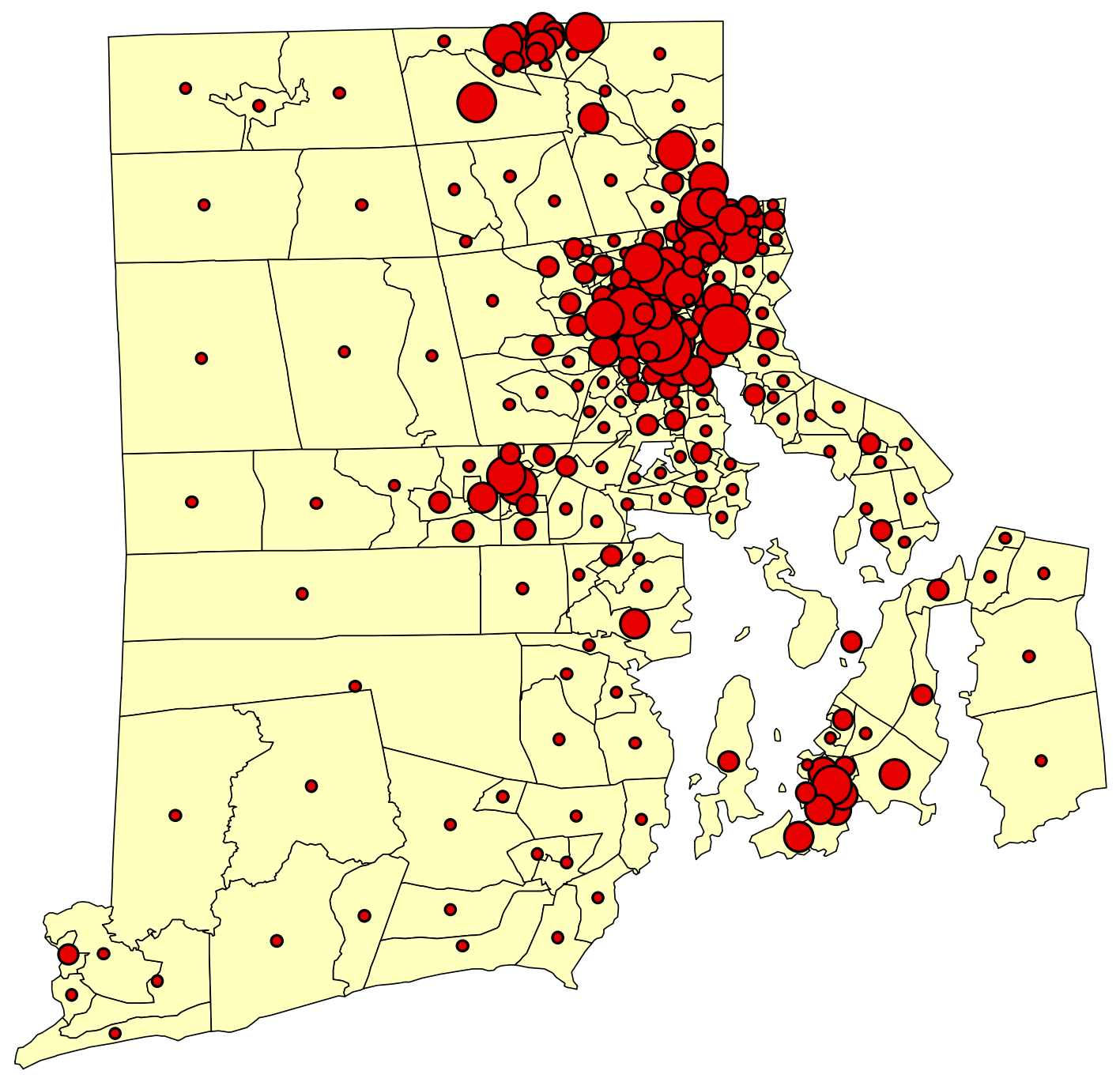

Lead Certificates as of $\mathbf{2 0 1 0}$

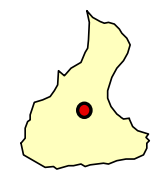

$\begin{array}{ll}\text { - } & -200 \\ 0 & 201-400 \\ \bigcirc & 401-600 \\ & 601-1000 \\ & 1001-1800\end{array}$ 
Figure 2: Certificates and 1997 Tract Characteristics
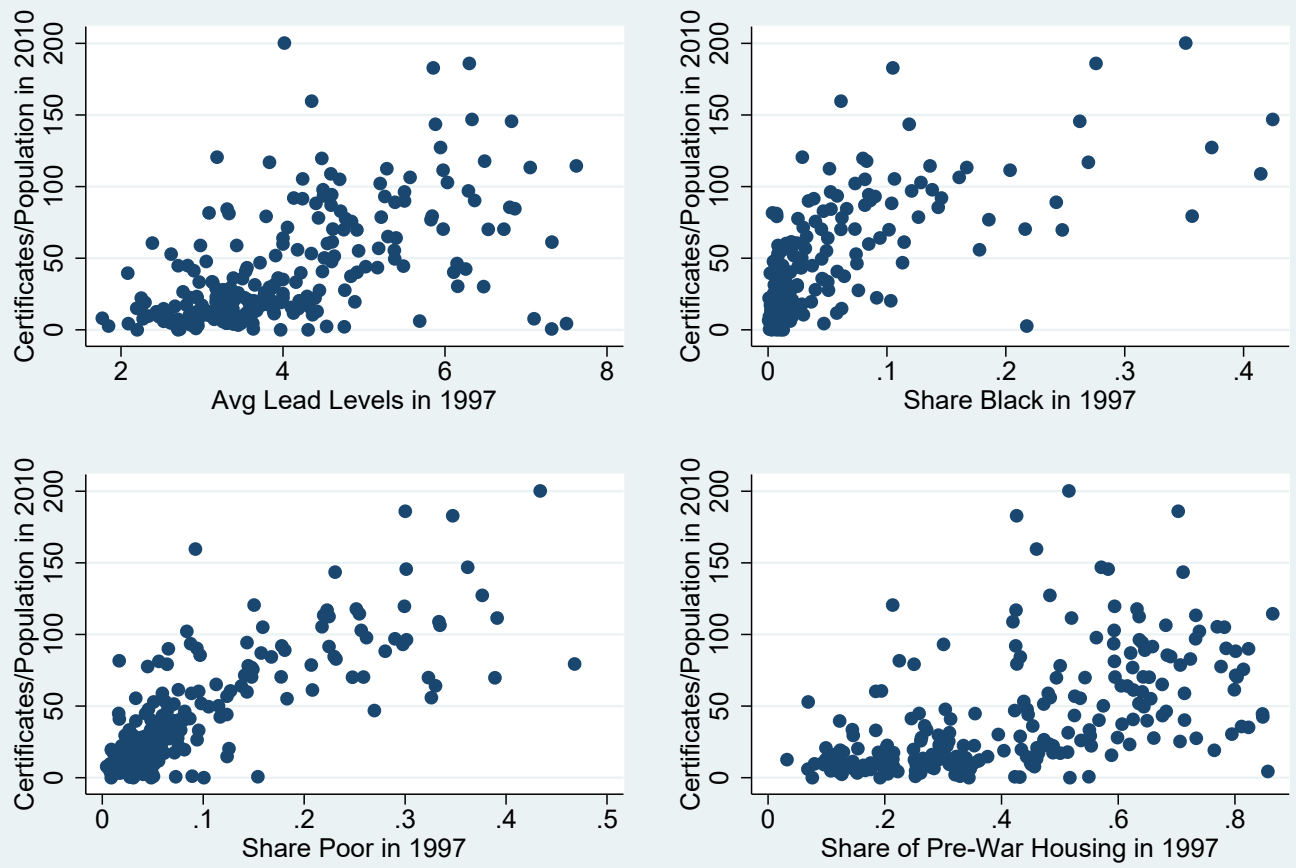
Figure 3: Certificates and Changing Tract Characteristics
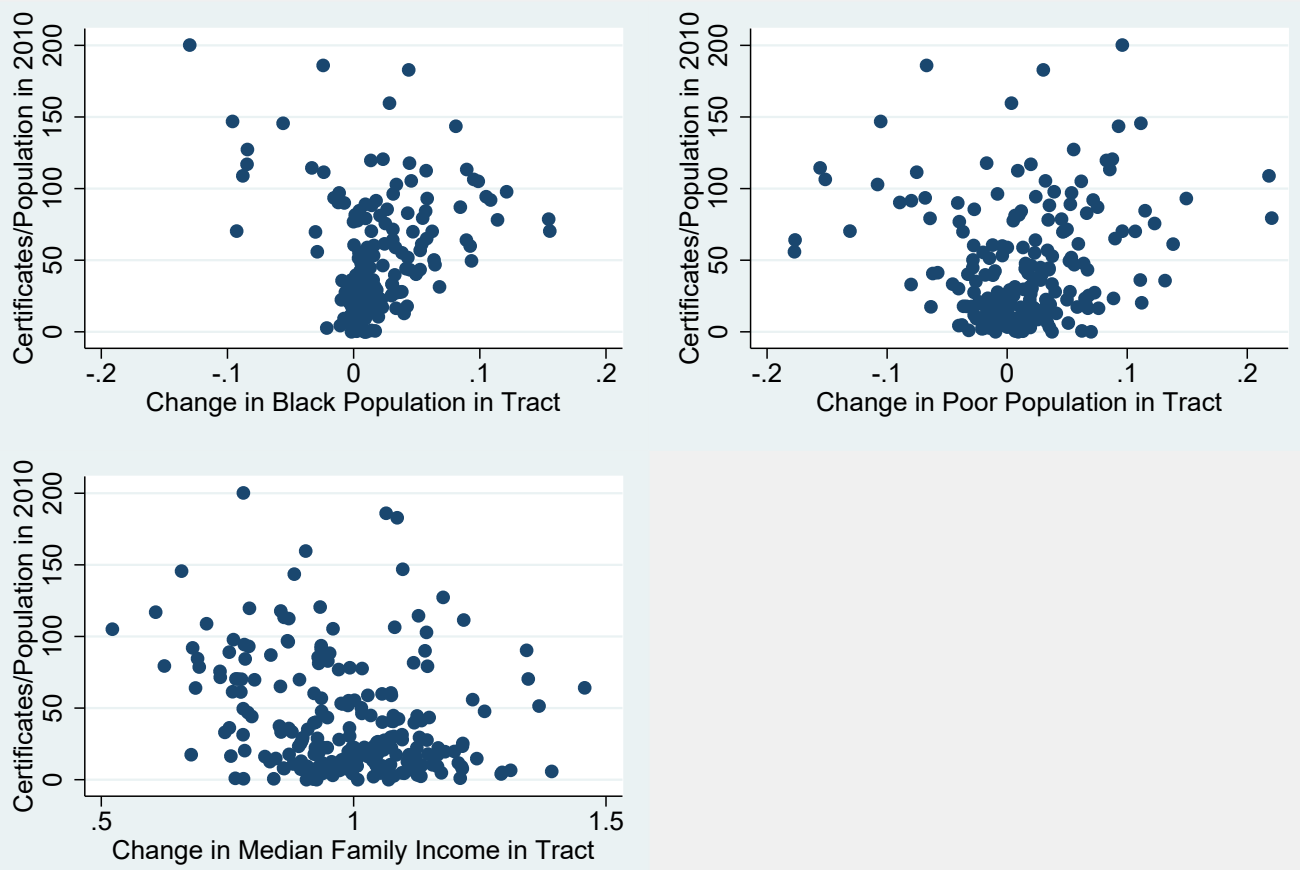


\section{Figure 4 Distribution of Lead by Birth Cohort}

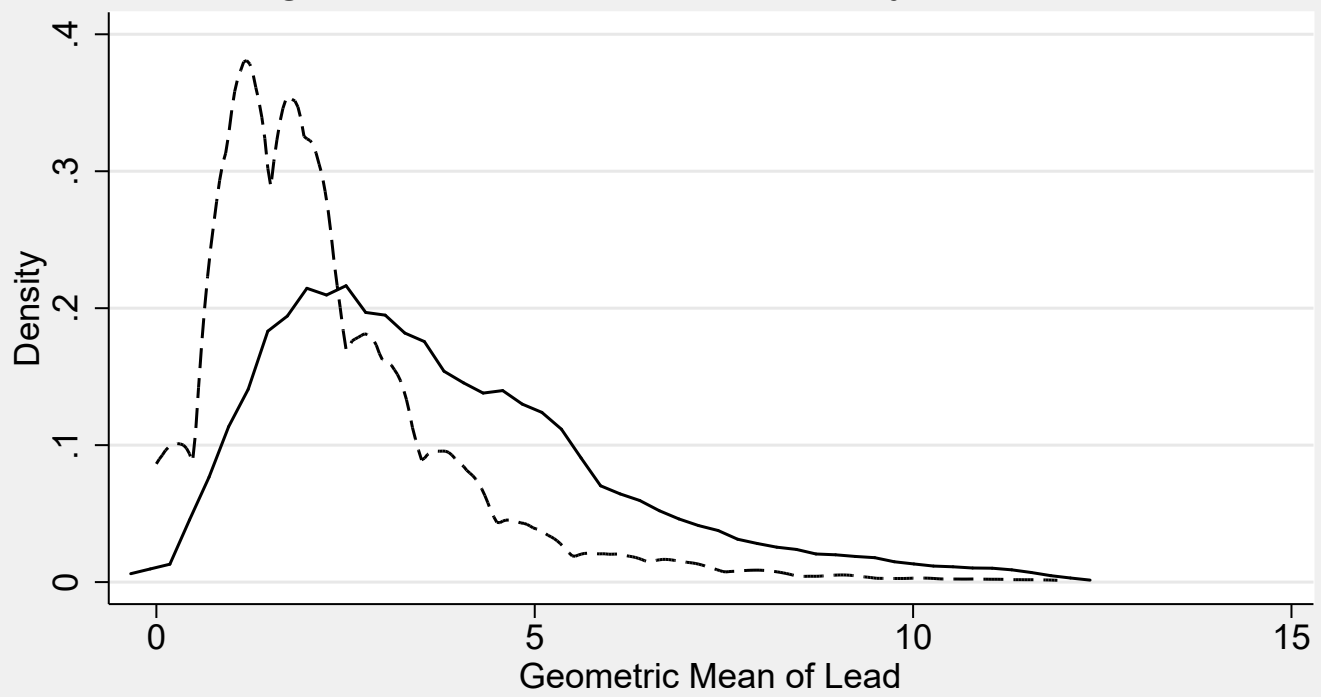

$$
\begin{array}{rr}
- & 1997 \\
----- & 2005
\end{array}
$$

kernel $=$ epanechnikov, bandwidth $=0.3385$ 